\title{
Theoretical Insights for Materials Properties of Cyclic Organic
}

\section{Nanorings}

\author{
Ángel J. Pérez-Jiménez Juan C. Sancho-García*
}

Prof. A. J. Pérez-Jiménez, Prof. J. C. Sancho-García

Department of Physical Chemistry,

University of Alicante,

E-03080 Alicante, Spain

Email Address: jc.sancho@ua.es

Keywords: Cyclic organic nanorings; Cycloparaphenylenes; CNT templates; supramolecular self-assembly; crystal engineering; organic molecular semiconductors.

\begin{abstract}
The synthesis of new carbon nanoforms with remarkable and fine-tuned bulk properties still represents a formidable challenge, with cyclic organic nanorings emerging in recent years for the template-driven design of this kind of systems. The design and engineering of these materials can be first controlled at the molecular scale, to further induce their specific self-assembly towards tailored properties at the nanoscale. Theoretical studies have lately contributed to the understanding of the underlying physical effects, the development of synthetic strategies, and the rationalization of novel materials properties, employing a variety of methods ranging from accurate calculations of isolated molecules to atomistic molecular dynamics simulations of a large sample of molecules in realistic conditions, which will be reviewed here with a focus on the transition from single-molecule to supramolecular properties.
\end{abstract}

\section{Introduction}

The oligomers of cyclic organic nanorings (e.g., CycloParaPhenylenes - CPPs, see Figure 1) have recently attracted a worldwide attention as radially oriented $\pi$-conjugated molecular materials [1-4]. The interplay between linear and radial conjugation [5], the lack of edge effects in these systems due to their cyclic topology [6], together with the tunability of their supramolecular properties as a function of size and the cavities (nanopores) created upon their self-assembly, has paved the way towards their scalable production as contemporary carbon nanomaterials with emerging applications largely differing from their (thoroughly studied) linear analogues. The last decade, from their first gram-scale synthesis by R. Jasti in 2008 [7], has witnessed a remarkable advancement of efficient and diverse synthetic routes, from pristine [8-34] or radical-ions [35-42], to the study of their optoelectronic, photophysical, semiconducting, and adsorption properties, to name just a few of them.

Actually, the self-assembled (solid-state) samples obtained for these systems has led to unique materials with impressive, distinctive, and tunable size-dependent applications $[43,44]$ such as: (i) size-selective encapsulation of optically active (e.g., fluorescent) guest molecules [45-50] and its fluorophore bioapplications [51] or its role as capturing agents [52]; (ii) controlled porosity and adsorption of small molecules in the cavities formed upon tubular-like self-assembly of the nanorings and its sensing applications [5355]; (iii) creation of mechanically interlocked nanomachines and nanosystems [56-60], macrocyclic homopolimerized compounds [61], lemmiscular systems [62,63], and Möbius belt-shaped nanorings [64, 65]; (iv) performance as organic molecular semiconductors with competitive properties (i.e., hole chargetransport mobilities) compared with other state-of-the-art organic systems [66], (v) quantum confinemente of surface-induced electronic states [67], etc. Note that these ambitious goals go well beyond the envisioned pioneering use of these nanorings as molecular templates for the controlled growth of Carbon NanoTubes (CNTs) of defined size, chirality, and edges [68-71]. Furthermore, in parallel to the evolution of the outstanding synthetic efforts and control over this set of unique materials-oriented properties, the use of modern theoretical models have largely contributed to the understanding and prediction of a wide number of features for these systems, tackling both single-molecule and supramolecular approaches, and thus providing key insights at the nanoscale which will be the main focus of the present report.

Among the large set of theoretical studies performed so far, early efforts mostly dealt with the evolution of the single-molecule geometrical, vibrational, electronic, strain, optical, and magnetic properties as a 
function of the oligomer size [72-84]. These remarkable studies were soon complemented with works addressing the detailed mechanism of growth of CNTs mediated by CPPs [85-92], and the host-guest encapsulation processes involving CPP nanorings [93-102] thus accompaying early experimental advances. Unless otherwise noticed, we will briefly present in the following sections only those (non-standard) theoretical methods and computational tools employed so far, emphasizing the physical reasons for that use, rather than to duplicate existing details already published with more standard methods.

Thereof, largely due to the emerging properties recently disclosed and exploited at the nanoscale, we will focus in the following on a set of the most recent (and hopefully novel) prospects of these materials including:

(i) the chemical and topological origin of the radical-like nature of closely related nanorings (i.e. CyclaCenes - CCs) compared with CPPs [103, 104], and the possible implications for the envisioned growth of armchair or zigzag CNTs $[105,106]$;

(ii) the comprehension of the driving forces for the supramolecular packing and cohesive energies of these systems as a function of their size [107], therefore opening a way to tune their supramolecular structure to access solid-state CNT-like structures via the adequate functionalization [108-110], and the determination of the preferred charge-transfer career paths $[111,112]$;

(iii) the differences between pristine and substituted CPPs [113-121], with emphasis on intra-molecular donor-acceptor compounds [122-124] displaying fluorescent and semiconducting properties upon specific functionalization [125];

(iv) the influence of structural units after changing phenylene by pyrenylene (i.e., CycloPYrelenes - CPYs) or ever larger structural motifs [126-128] and its effect on the single-molecule [129] and supramolecular properties [130]; and finally

(v) the process of physisorption and molecular friction of these systems on e.g. graphite surfaces [131], which could modulate a highly directional growth of solid-state samples, as well as the emerging semiconducting properties of the deposited monolayer upon diffusion of the charge carriers injected from the surface [132].

\section{Nanorings as individual molecules with a unique shape}

\subsection{Topological effects on electronic structure and reactivity}

The shape of these nanorings (i.e., the way in which the benzene or monomer units are connected) determines in fact their electronic structure, based on electron-correlation effects which are sometimes beyond the treatment by standard (i.e., single-reference) methods. Some theoretical studies [104,133,134] have revealed significant differences in electronic properties such as aromaticity or static (also called strong) correlation effects depending on how the rings (i.e., chemical units) are fused and/or connected until closing the loop. Figure 2 summarizes the findings of applying non-standard methods able to cost-effectively capture all-range electronic correlation effects [135-137]. Comparing CPP and CC nanorings of increasing size, dubbed as nCPPs and nCCs in the following, respectively, with $\mathrm{n}$ indicating the number of rings connected or fused, one can observe how the former keeps a non-radical (closed-shell) nature while the latter are considered di- or tetraradicaloids depending on $\mathrm{n}$, and thus elusive in principle to common synthetic routes and also to standard calculation methods. Furthermore, the even or odd number of rings also determines the extent of the radical-like character, which is another direct consequence of topological effects.

However, minor structural changes (i.e., topological defects) of the CC forms could reduce significantly their radicaloid nature thus allowing their final synthesis. For instance, theoretical studies of annelated 
pentagon-heptagon rings (i.e., [5.7 $\left.]_{n} \mathrm{CCs}\right)$ [138], hexagon-octagon rings (i.e., [6.8 $\left.]_{n} \mathrm{CCs}\right)[139-142]$ or pentagonhexagon rings (i.e., [5.5.6 $\left.]_{n} \mathrm{CCs}\right)[143]$ has been shown to lead to closed-shell systems. Doping with B, N or Si atoms seems to also increase their synthetic affordability [144-147]. Remarkably, very recently a set of cyclic molecules composed of fully fused (but distorted from a perfect loop) edge-sharing benzene rings was synthesized and crystallized [148-152], in agreement with the results outlined here. On-surface synthesis of CCs has also been explored with partial success [153]. These findings show the potential use of these systems as molecular templates for the growth of well-shaped carbon nanotubes, upon controlling the topology of the nanorings, as well as the quality of theoretical tools used for anticipating and thus guiding the molecular design.

Those results have also allowed to explore the consequences for the controlled growth of armchair or zigzag CNTs of various diameters and lengths, and more specifically how this could benefit from the use of nCPPs and nCCs molecular templates, respectively, of varying size. Interestingly, the chemical nature of individual CPPs allows a moderate radicaloid character of armchair CNTs of increasing size built from them [132], which translates in practice towards the successful synthesis of extended CPP rings [154-156] or even armchair CNTs with the same diameter than a 12CPP system used as template [70]. Several synthetic routes have also been theoretically explored to better understand the complex mechanism and activation barrier heights for this growth; e.g., through a radical-mediated mechanism involving CPP and $\mathrm{C}_{2} \mathrm{H}_{2}$ species as reactants [91], in line with previous experimental cycloaddition (diene - dienophile) studies [157]. A recent analysis also relates CPP strain energy to reactivity: localizing, visualizing, and quantifying strain energies of nanorings [158]. Contrary to this, the use of CCs to grow the corresponding zigzag CNT seems, on the other hand, a much more complicated issue since the significant radicaloid character is preserved in the tubes independently of their length and diameter. This effect can be observed in Figure 3 where succesive layers of CCs are fused to grow a single-walled (and short) CNT as a proof of concept. The non-negligible radicaloid character always concentrates on the edges, independently of the system size, which helps to explain the high reactivity of these compounds. The atomiclevel structural control for their synthesis is thus expected to benefit from theoretical insights in the future too.

\subsection{Theoretical methods and computational tools}

Density Functional Theory (DFT) has been usually adopted to calculate geometrical and electronic groundstate properties, or excited-state properties via its Time-Dependent (TD-DFT) variant, of hoop-shaped systems. In standard DFT calculations, where the electronic structure is well represented by a Slater determinant, the ground-state electronic density is built upon the lowest $N$ occupied spin-orbitals $\varphi_{i}$ as:

$$
\rho^{\mathrm{DFT}}(\mathbf{r})=\sum_{i}^{N} n_{i}\left|\varphi_{i}(\mathbf{r})\right|^{2},
$$

with the corresponding energy levels given by $\varepsilon_{i}$, and the total energy by $E[\rho]=T_{s}[\rho]+\int \rho(\mathbf{r}) v(\mathbf{r}) d \mathbf{r}+$ $U[\rho]+E_{x c}[\rho]$, with all the terms having their usual meaning. Since degeneracies do not often arise in common systems, the $\alpha$ (or $\beta$ ) orbital occupation numbers $n_{i}$ are 0 or 1 , for occupied and virtual orbitals respectively, and DFT leads normally to accurate results. This is the common case of CPPs and their linear analogues, but not the situation found for CCs or closely related systems. For the latter case, the Tight-Binding model already predicts the existence of both zero-energy states and quasi-zero-energy states for even and odd n values of nCCs [106, 159], or in the language of molecular orbital theories, the frontier orbitals are degenerate for both odd and even systems: CCs with an even (odd) number of rings present two (four) electrons in (a pair of) two completely degenerate orbitals, thus behaving as diradical (polyradical) systems. Theoreticians had studied early the hypothesized structure of cyclacenes in the 1950s and 1960s, together with other cyclic polyenes at the Hückel level $[160,161]$, already paving the way towards the understanding of their geometrical and electronic structure. Note also that any deformation, distortion or doping of the perfect loop indeed breaks 
that degeneracy and thus reduces the radical character of the systems facilitating indeed their synthesis. Interestingly, the ultimate origin of these zero-energy modes relies on the structural symmetry, commuting with the sublattice operator [162], which can be lifted upon local distortions. Furthermore, the radical nature of linear acenes is known to also increase with the system size, but the cyclic topology seems to exacerbate this character. A commonly adopted solution is to impose a broken-symmetry calculation for (singlet) open-shell systems, but this introduces spin-contamination (also scaling unfavourably with size [163]) and thus compromises the energy of the low-spin solution [164].

Deviations from a routine DFT treatment are typically associated with the presence of strong electron correlations [165], and can be rectified by the introduction of fractional occupation numbers $f_{i}$, as it naturally happens in other ab initio multi-configurational theories where more than one Slater determinant is used to represent the chemical system under study [166]. The Finite-Temperature (FT-) DFT method employed herein relies on mimicking this expected fractional occupation of molecular orbitals induced by (near-)degeneracy effects, with the associated density written now as:

$$
\rho^{\mathrm{FT}-\mathrm{DFT}}(\mathbf{r})=\sum_{i}^{\infty} f_{i}\left|\phi_{i}(\mathbf{r})\right|^{2},
$$

and $f_{i}$ the corresponding fractional occupation numbers $\left(0 \leq f_{i} \leq 1\right)$. After defining the Gibbs electronic free energy $\left(G_{e l}=E_{e l}-T_{e l} S_{e l}\right)$ of the system at a electronic (but fictitious) pseudo-temperature $T_{e l}$, that energy is then minimized to obtain the $f_{i}$ values by a Fermi-Dirac distribution around the Fermi energy level $E_{F}$ :

$$
f_{i}=\frac{1}{1+e^{\left(\epsilon_{i}-E_{F}\right) / \theta}},
$$

depending on $\theta=k_{B} T_{e l}$. One can also define a Fractional Orbital Density (FOD) $[136,137]$ for a subset of the obtained $\phi_{i}(\mathbf{r})$ such as:

$$
\rho^{F O D}(\mathbf{r})=\sum_{i}^{M}\left(\delta_{1}-\delta_{2} f_{i}\right)\left|\phi_{i}(\mathbf{r})\right|^{2},
$$

where $\delta_{1}$ and $\delta_{2}$ are chosen to become $(1,1)$ if the single-particle energy level $\left(\epsilon_{i}\right)$ associated with the orbital $\phi_{i}$ is lower than the energy of the Fermi level, $E_{F}$, or $(0,-1)$ otherwise. This density can also be integrated to estimate the number of strongly correlated (i.e., unpaired) electrons, $N_{F O D}$ :

$$
N_{F O D}=\int \rho^{F O D}(\mathbf{r}) d \mathbf{r} .
$$

Note the similarities between this method and the Thermally-Assisted-Occupation (TAO) DFT method of Chai et al. [167-169] also applied to organic nanorings with similar results [170]. For a pure closedshell (non-radical) system $N_{F O D} \rightarrow 0$, while for a pure open-shell (biradical) system $N_{F O D} \rightarrow 2$, with the intermediate situations defined as radicaloids. If $N_{F O D}>2$ one deals with (poly)radical(oids) instead. This method thus allows the qualitative (i.e., 3D visualization of $\rho^{F O D}(\mathbf{r})$ ) and quantitative (i.e., $N_{F O D}$ and energy difference between low- and high-spin states) treatment of CC systems, which is far from being correctly achieved by standard DFT. The results of the FT-DFT method for nCCs compare favourably with those of more sophisticated yet costly methods, as truly multi-configurational approaches [171]. We also emphasize the close agreement found with the Restricted Active Space Spin-Flip (RASSF) method [135], which is known to lead to accurate results for real-world radical(oid) systems [172175]. The FT-DFT method is implemented in the ORCA [176] (version 4.0) quantum-chemical package, employing tight convergence and integration thresholds, with the fractional orbital density plots obtained by the UCSF-CHIMERA [177] (version 1.12) package. 


\section{From single-molecule to supramolecular bulk structures}

\subsection{Understanding the crystalline growth and packing}

The successful synthesis of CPPs of increasing size and diameter has prompted the study and characterization of their solid-state samples. As it happens for other polycyclic aromatic hydrocarbons, the packing of nanorings mostly follows a herringbone pattern, see the cases of 5CPP, and 7-12CPPs in Figure 4. In these cases, the typical edge-to-face orientation of a pair of interacting organic molecules evolves towards a configuration minimizing the void left by the nanoring cavities, often filled with solvent molecules occluded, while maximizing the weak intermolecular interaction energies, thus creating a porous lattice structure $[178,179]$. Particularly interesting is the case of $6 \mathrm{CPP}$, for which a tubular-like structure was initially disclosed but with several polymorphs later found close in energy [180]. While the tubular-like packing could create one-dimensional nanochannels for weak guest sorption, the herringbone packing could afford tightened trapped guest molecules. The combination of these unique nanometric features, such as light weight together with high absorption capacity, shows the versatility of these materials upon molecular engineering [181].

The analysis of the stability of the weak interactions found between neighbouring pairs of CPP molecules, extracted from the crystalline structures, has also shed light about the reasons for the favoured packing motifs of the 5-12CPP systems $[182,183]$. In all cases, even for the smallest 5CPP and 6CPP systems, a very stable dimer is always found with an energy comprised between -12 and $-14 \mathrm{kcal} / \mathrm{mol}$ with respect to the isolated molecules, increasing to values around $-18 \mathrm{kcal} / \mathrm{mol}$ for $10 \mathrm{CPP}$ and $12 \mathrm{CPP}$, which shows the relationship between bulk and molecular structures. The cohesive (or lattice) crystal energy of these organic solids can also be estimated by theoretical methods [184-186], ranging from 52 to 57 $\mathrm{kcal} / \mathrm{mol}$ for $6 \mathrm{CPP}$ and $12 \mathrm{CPP}$, respectively [107]. The contribution of each pair of interacting molecules to this (global) cohesive energy helps to understand the differences between e.g. the tubular-like packing of $6 \mathrm{CPP}$ and the herringbone packing of 12CPP: while for the former the perfectly aligned (or superimposed) dimers contributed the most to the value of the cohesive energy, these dimers do not have the same importance in the case of the latter, with the herringbone-like dimer dominating the final values. The substitution of phenylene by larger pyrene units [127, 128] does not change the preferred herringbone packing of the formed CPY nanorings, observing again a limited number of configurations: parallel, herringbone, and tubular-like dimers [130]. Similarly to the CPP case, the slipped tubular-like dimer is favoured with respect to the other two main dimers found, but the higher number of the latter in the unit cell dominates the final crystalline packing, and leads now to a cohesive energy of $69 \mathrm{kcal} / \mathrm{mol}$ and thus sligthly larger than those calculated for CPPs of approximately the same diameter.

\subsection{Crystal engineering of materials}

This accumulated understanding at the molecular scale has also made possible to fine-tune the crystal packing of CPPs, from herringbone-like to tubular-like, upon specific functionalization (i.e., fluorination) thanks to the strength and directionality of the weak $\mathrm{C}-\mathrm{F} \cdots \mathrm{H}$ interactions. With this in mind, 10CPP and 12CPP bearing symmetrically placed tetrafluorophenylene moieties were recently synthesized and their X-ray crystal structure fully resolved $[187,188]$. These molecules self-assembled into perfectly aligned columns, creating accesible nanochannels mimicking actually those found in CNTs. The complementary theoretical analysis performed revealed the key intermolecular interactions contributing the most to this specific packing, not only between superimposed molecules (driven by complementary $\mathrm{C}-\mathrm{F} \cdot \mathrm{H}$ interactions) but also between adjacent columns (driven by quadrupole-quadrupole interactions). The crystal engineering of nanorings [189], upon modulation of specific intermolecular interactions, definitively opens a new path to porous or semiconducting materials, and of course benefits from the latest theoretical advances to deal with intermolecular interactions at all distances and orientations. 


\subsection{The role of graphite surface}

The physisorption of CPPs on substrates might further influence the final supramolecular organization of the samples and thus assisting the process of formation of CNTs, for instance, after inducing an epitaxial bottom-up (nanochannel-like) layer-by-layer growth [187]. The detailed interaction of 8CPP and graphene nanoflakes [131] has revealed the underlying competition between $\pi \cdots \pi$ and $\mathrm{CH} \cdots \pi$ interactions, depending on the relative orientation of the deposited nanoring with respect to the surface (see Figure 5). The physisorption energy for the latter configuration was found twice as high as that for the $\pi \cdots \pi$ interaction, probably due to a much larger surface contact between both molecule and substrate, with the closest surface-molecule distance around $3.3-3.4 \AA$, as also found for the encapsulation of $\mathrm{C}_{60}$ or $\mathrm{C}_{70}$ by 10-12CPP $[190,191]$ or, in general, for non-covalent interactions between organic nanoforms [192]. Once physisorbed, the molecules also found little resistance to diffuse on the surface, giving rise to nanoislands at low surface concentration what could also be rationalized by the computational simulations performed. Note that the roughness of graphite is very low, and thus this behaviour could be different in other surfaces (e.g., silica). If more molecules are progressively deposited on the surface to reach a full coverage, two stable configurations are found [132] as shown in Figure 5: (i) a hexagonal structure arising from horizontally physisorbed molecules, consequence (but not only) of the $\mathrm{CH} \cdots \pi$ molecule-substrate interactions; and (ii) a rectangular structure of vertical, concave-convex arranged molecules, consequence (but not only) of the $\pi \cdots \pi$ molecule-substrate interactions.

\subsection{Theoretical methods and computational tools}

Since the crystal packing is based on dimer (or periodic) interactions, which actually depend on the operating non-covalent (weak) intermolecular forces between molecules, we will focus on the methods employed so far to incorporate this dominant dispersion interactions, not only for hoop-shaped systems but for any organic crystal: when two mutually polarizable chemical systems are close enough, as it happens in organic cystals, the response of the electronic cloud of a system to the presence of instantaneous and fluctuating charge densities from another molecule induces a stabilization energy [193, 194] driving ultimately their self-assembly or supramolecular organization. Unfortunately, uncorrected DFT fails to incorporate these medium- to long-range effects (note that dispersion forces operate at distances larger than the van der Waals atomic radii) due to the short-sighted treatment of matter imposed by the dependence of common (semi-local) functionals only on the density $(\rho)$ and its gradient $(\nabla \rho)$, needing thus some additional correction [195].

The most employed dispersion correction is probably the D3(BJ) method [196, 197], recently updated to the D4 version [198], which incorporates in a simple but realistic way the pairwise additive interactions between all atoms, $A$ and $B$ separated by the distance $R_{A B}$, as:

$$
E_{\mathrm{D} 3(\mathrm{BJ})}\left(R_{A B}\right)=-\sum_{n=6,8} s_{n} \sum_{B>A}^{\text {atom pairs }} \frac{C_{n}^{A B}}{R_{A B}^{n}+f_{n}\left(R_{A B}^{0}\right)},
$$

depending on: (i) $s_{n}$, a functional-dependent parameters coupling electronic and dispersion energies; (ii) $C_{n}^{A B}$, the $n$ th-order interatomic dispersion coefficients (iii) $f_{n}=\left(a_{1} R_{A B}^{0}+a_{2}\right)^{n}$, a damping function to switch the energy from medium- to short-distances, with $R_{A B}^{0}=\sqrt{\frac{C_{8}^{A B}}{C_{6}^{A B}}}$ and $\left(a_{1}, a_{2}\right)$ again functionaldependent parameters fitted. Note that once corrected, practically any DFT exchange-correlation functional of choice could be thus safely employed for this kind of calculations, with the final energy being now $E[\rho]=T_{s}[\rho]+\int \rho(\mathbf{r}) v(\mathbf{r}) d \mathbf{r}+U[\rho]+E_{x c}[\rho]+E_{\mathrm{D} 3(\mathrm{BJ})}$, and with all the terms having their usual meaning. Another way to incorporate the (missing by default in DFT) non-covalent interactions is to employ a Non-Local (NL) correction to the correlation energy functional $\left(E_{c}[\rho(\mathbf{r})]\right)$ in the form:

$$
\Delta E_{c}\left[\rho(\mathbf{r}), \rho\left(\mathbf{r}^{\prime}\right)\right]=\int d \mathbf{r} \rho(\mathbf{r})\left[\frac{1}{2} \int d \mathbf{r}^{\prime} \rho\left(\mathbf{r}^{\prime}\right) \Phi\left(\mathbf{r}, \mathbf{r}^{\prime}\right)+\beta(b)\right],
$$


whose function $\Phi\left(\mathbf{r}, \mathbf{r}^{\prime}\right)$ couples the $\rho(\mathbf{r})$ and $\rho\left(\mathbf{r}^{\prime}\right)$ electronic densities while keeping the correct $\mid \mathbf{r}-$ $\left.\mathbf{r}^{\prime}\right|^{-6}$ asymptotic behaviour. Probably the most extended final form of $\Phi\left(\mathbf{r}, \mathbf{r}^{\prime}\right)$ is the VV10 construction $[199,200]$. Note that the functional-dependent parameter $b$ can also be obtained independently of the functional choice [201-203]. The $\Delta E_{c}\left[\rho(\mathbf{r}), \rho\left(\mathbf{r}^{\prime}\right)\right]$ energy is normally added non-self-consistently to the correlation energy, although self-consistency is also possible yet costly with minor changes in the density and associated properties.

The cohesive crystal energy can be estimated by bulk periodic boundary conditions, or equivalently by considering all the 1st.- and 2nd.-shell interactions between different molecular pairs [204-206], by the expression:

$$
E_{\text {cohesive }}=\frac{E_{\text {bulk }}}{Z}-E_{\text {molecule }}
$$

where $E_{\text {bulk }}$ is the total energy of the unit cell considered, including $Z$ molecules, and $E_{\text {molecule }}$ is the energy of an isolated molecule, both energies needing to include dispersion corrections at the same level. Note that the dimer interaction energies are calculated as $\Delta E=E_{\text {dimer }}-2 E_{\text {molecule }}$, with the resulting cohesive energy is this case given by $E_{\text {cohesive }}=-\sum_{a b c}\left(n_{a} \cap n_{b} \cap n_{c}\right) \Delta E_{a b c}$ for the number $\left(n_{a}, n_{b}\right.$ or $n_{c}$ ) of all possible dimer configurations along the crystalline directions $a b c$. For supramolecularly nanostructured forms, one can also add a three-body (but small) correction [207,208] to the dispersion energy given again by the D3(BJ) expression:

$$
E\left(R_{A B}, R_{A C}, R_{B C}\right)=\sum_{C>B>A}^{\text {atom triples }} C_{9}^{A B C} \frac{\left(3 \cos \theta_{A B} \cos \theta_{B C} \cos \theta_{A C}+1\right)}{\left(R_{A B} R_{B C} R_{A C}\right)^{3}} f_{n}\left(\bar{R}_{A B C}\right),
$$

where $C_{9}^{A B C}$ is the corresponding $n$ th-order interatomic dispersion coefficient approximated by $C_{9}^{A B C}=$ $-\sqrt{C_{6}^{A B} C_{6}^{B C} C_{6}^{A C}}$, and $\theta_{k}$ are the internal angles between the internuclear distances $R_{A B}-R_{B C}-R_{A C}$. Both forms of tackling the cohesive energy lead to similar values.

The energy profile for modelling the competition between $\pi \cdots \pi$ and $\mathrm{CH} \cdots \pi$ interactions, representative of the deposition process of CPPs with respect to a graphite (or any other) surface, taken into account the large size of the composed system, has been obtained by a cost-effective method called HF$3 \mathrm{c}[209]$ :

$$
E_{\mathrm{HF}-3 \mathrm{c}}=E_{\mathrm{HF} / \mathrm{MINIX}}+\underbrace{E_{\mathrm{D} 3(\mathrm{BJ})}+E_{\mathrm{BS}}^{g C P}+E_{c R_{A B}}}_{\text {corrections }},
$$

with the four different terms representing: (i) the Hartree-Fock (HF) energy with a minimal basis set (MINIX); (ii) the dispersion correction of the form D3(BJ) given by Equation (6); (iii) a geometrical Counterpoise Correction (gCP) to account for Basis Sets (BS) incompleteness issues; and (iv) a final correction dealing with the systematic overestimation of covalent bond distances $\left(R_{A B}\right)$ between atoms $A$ and $B$ by the HF/MINIX method. The clear advantage of this composite method is its reduced computational cost compared even to DFT-D3(BJ) still being very competitive in accuracy. Note that this family of methods is also extended to B97-3c and other variants [210], including the use of periodic boundary conditions [211] and always keeping a very good trade-off between accuracy and computational cost. Additionally, the Density-Functional Tight-Binding (DFTB) method [212, 213] could also constitute a alternative to this kind of calculations. All the reported DFT-D3(BJ), DFTNL, and HF-3c calculations were done with the ORCA [176] (version 3.0 or higher) quantumchemical package. The calculations with periodic boundary conditions were done with the ABINIT code [214, 215]. The MERCURY [216] (version 3.10) tool was also used or the visualization and manipulation of crystallographic data.

These adsorption energy profiles were further used to calibrate a force-field expression [132]; i.e., optimizing the Lennard-Jones parameters to fit the curves previously calculated at the HF-3c level. Partial atomic charges of the adsorbate were calculated by fitting to the electrostatic potential, and then 
used to feed the force-field. Complementarily, the force-field expression also reproduced the intermolecular interaction energies of representative dimer configurations of CPPs, extracted from their crystalline structure, only slightly underestimating the HF-3c results. As a further step, the crystalline structure of $8 \mathrm{CPP}$ was simulated at a temperature of $300 \mathrm{~K}$ and $1 \mathrm{~atm}$ of pressure for $10 \mathrm{~ns}$, reaching the equilibration in the very first picoseconds. The error in cell dimensions were less than $2 \%$ compared to experimental results, in line with previous calculations for organic crystals [217]. Therefore, with a tailored force-field expression able to reproduce accurately geometrical and intermolecular magnitudes of CPP systems, and used to study the self-aggregation process of CPP molecules on a graphite surface, more insights at the nanoscale about the collective supramolecular behavior are expected in further studies.

All the atomistic (force-field and molecular dynamics) simulations were performed with the NAMD (version 2.11) package [218] and the VMD tool [219] was employed for the representation of the simulations snapshots.

\section{Semiconducting charge-transport properties}

\subsection{Supramolecular charge-carrier mobilities}

The mesoscale morphology of samples made from organic molecular semiconductors is known to govern the final charge-carrier mobilities upon a drift migration induced by an externally applied electric field $[220,221]$. Once the charges are injected into the bulk, the magnitudes known as reorganization energy (i.e., an intramolecular energy needed to distort the molecular geometry when the charge is molecularly retained) and electronic coupling (i.e., an intermolecular energy depending on the electronic overlap between every pair of neighbouring molecules) determine the charge-transfer rates at the molecular scale. The associated mobility can thus be obtained after simulating all the hopping events taken place within the bulk, with the crystalline order significantly influencing the final values [222] since it determines the charge-carrier paths and traps. Recent experimental studies in CPP samples [66] gave hole mobilities as high as $2 \mathrm{~cm}^{2} \cdot \mathrm{V}^{-1} \cdot \mathrm{s}^{-1}$, and thus competitive with other predictions for small state-of-the-art molecules as rubrene, tetracene, rubicene, or pentacene $[223,224]$ although still smaller than the highest experimental values reported in literature for organic molecular semiconductors. The intrinsic disorder of the samples, due to e.g. intermolecular or vibronic effects, is also known to have some impact on the final estimates of mobilities through variations of the electronic coupling values [225,226].

Theoretical studies have also shed light about the relative importance of both molecular magnitudes (reorganization energies and electronic couplings) on final mobility values of crystalline samples, with reorganization energies decreasing with the nanoring size [111], as expected due to the larger electronic delocalization, and moderate (and almost constant) electronic coupling values along the sequence of the 5-12CPPs systems studied [66]. The detailed analysis of the calculated electronic couplings (e.g., 6CPP, $8 \mathrm{CPP}$, and 12CPP) along all the possible supramolecular paths [112] (see again Figure 4) allows one to reach the following conclusions: (i) the electronic couplings are generally negligible for tubular-like arrangements, due to the exponential decay with the intermolecular distance, which is necessarily large here due to the $\mathrm{CH} \cdots \mathrm{CH}$ mutual orientations of these superimposed dimers; (ii) the herringbone-like dimers do not give rise to the largest values neither; and (iii) the slipped face-to-face orientation of the dimers found between layers of molecules leads to the highest values found, thus identifying the highmobility crystalline plane. Briefly, for these nanorings, the inter-layer charge transport mechanism (due to the favourable slipped-lateral dimer arrangements found) is more efficient than the intra-layer counterpart. The introduction of pyrene units (CPYs) has also been studied [130], for both 3-Cyclo-2,7-pyrenylene (3CPY) and 4-Cyclo-2,7-pyrenylene ([4CPY) compounds, leading to smaller reorganization energy values with respect to CPPs of the same diameter but also to smaller electronic coupling values. The pyrene units, on the other hand, offer a more versatile template for substitutions in ipso and ortho positions, with the effect of electroactive atoms (i.e., F, Cl, Br) and groups $(\mathrm{CN})$ recently studied allowing thus to anticipate the use of these systems as organic (ambipolar) molecular semiconductors [227]. 
To fully rationalize these effects in CPP samples, Figure 6 shows (through the example of $8 \mathrm{CPP}$ ) how the electronic coupling values might change upon variations of the intermolecular distance and/or mutual orientation, for a vast set of (forcefully idealized) relative configurations envisioned in crystal structures. The results can be qualitatively rationalized from the distribution of the Highest Occupied Molecular Orbital (HOMO) and Lowest Unoccupied Molecular Orbital (LUMO) orbitals which, although fully delocalized along the nanoring, is well-known to dramatically alter the electronic coupling values even for a small displacement of one molecule with respect to another, depending on bonding or antibonding combinations of these orbitals in the dimer configuration [228]. The calculation of the electronic coupling values for the monolayers formed upon physisorption to a graphite surface yielded to hole (electron) mobility values of $5.6(1.7)$ and $0.1(0.3) \mathrm{cm}^{2} \cdot \mathrm{V}^{-1} \cdot \mathrm{s}^{-1}$ for the hexagonal and concave-convex configurations described before, respectively [132]. These values, slightly higher than those found for bulk hole mobilities [66], might indicate a stronger disorder of real samples with respect to the monolayer investigated as a model case. For the field of Organic and Molecular Electronics, note that: (i) other transport regimes (e.g., metal-doped 6CPP coupled with Au electrodes exhibiting negative differential resistence $[229,230]$ ) have also been explored; (ii) CPPs have also been proposed as additives to improve the electrical and mechanical (stretchability) properties of polymer-based semiconductors [231].

\subsection{Donor-Acceptor systems}

Prompted by the availability of the crystal structure of N,N-dimethylaza-8-CPP, DMA-8-CPP in the following, the semiconducting properties of this molecule has also been recently investigated [112] and compared to $6 \mathrm{CPP}, 8 \mathrm{CPP}$, and $12 \mathrm{CPP}$. Note that another $\mathrm{CPP}$ derivative, namely 4-cyclo-N-ethyl-2,7carbazole also with radially oriented $\pi$-orbitals, has been recently incorporated [232] in an Organic FieldEffect Transistor (OFET) with low experimental mobilities $\left(\approx 10^{-5} \mathrm{~cm}^{2} \cdot \mathrm{V}^{-1} \cdot \mathrm{s}^{-1}\right)$ but in agreement with those experimentally found for 10CPP [233] too. First of all, the hole and electron reorganization energies of DMA-8-CPP are similar, and in the case of holes, slightly higher than that calculated for undoped $8 \mathrm{CPP}$, thus indicating a more favoured n-type or ambipolar performance in this case if the rest of conditions remain the same. The detailed analysis has revealed a strong contribution to reorganization energies from low-frequency modes related to the radial breathing modes, previously detected in Raman measurements [234-236], with most of the other frequency contributions in the $1200-1600 \mathrm{~cm}^{-1}$ range. The analysis of the crystal structure of DMA-8-CPP and the corresponding electronic coupling calculations indicates, however, a significant increase of the p-type coupling with respect to the n-type one, and a much higher value of the former than for pristine $8 \mathrm{CPP}$. This translates into a much higher (but also highly anisotropic) hole charge-transfer rate for DMA-8-CPP than for 8CPP. Host-guest systems based on CPPs donor and fullerene acceptors $\left(\mathrm{C}_{60}\right.$ and $\mathrm{C}_{70}$, respectively, encapsulated by 10CPP and $11 \mathrm{CPP}$ ) have also been theoretically studied [237], with hole (electron) transport mobilities in the range of $10^{-3}-10^{-1} \mathrm{~cm}^{2} \cdot \mathrm{V}^{-1} \cdot \mathrm{s}^{-1}\left(10^{-5}-10^{-3} \mathrm{~cm}^{2} \cdot \mathrm{V}^{-1} \cdot \mathrm{s}^{-1}\right)$, and thus with potential for its use in organic photovoltaic applications $[238,239]$ as recently explored for conjugated macrocycles too [240].

\subsection{Theoretical methods and computational tools}

The migration of charge-carriers, holes or electrons, across the organic crystal is often modeled through a concerted sequence of charge-transfer events [241]. That process thus involves a pair of neighbouring molecules, one acting as the donor and the nearest neighbour one as the acceptor, after the effective chargeinjection process from the corresponding reservoirs [242,243]:

$$
\begin{aligned}
& \mathrm{CPP}^{\cdot+}+\mathrm{CPP} \longrightarrow \mathrm{CPP}+\mathrm{CPP}^{\cdot+}, \\
& \mathrm{CPP}^{--}+\mathrm{CPP} \longrightarrow \mathrm{CPP}+\mathrm{CPP}^{\cdot-} .
\end{aligned}
$$

Thus, the reorganization energy can be calculated as $\Lambda^{++}=\left[E_{\mathrm{CPP}^{++} / / \mathrm{CPP}}-E_{\mathrm{CPP}^{++}}\right]+\left[E_{\mathrm{CPP} / / \mathrm{CPP}++}-E_{\mathrm{CPP}}\right]$ or $\Lambda^{--}=\left[E_{\mathrm{CPP}-} / / \mathrm{CPP}-E_{\mathrm{CPP}-{ }^{--}}\right]+\left[E_{\mathrm{CPP} / / \mathrm{CPP}^{--}}-E_{\mathrm{CPP}}\right]$, for holes and electrons, respectively, thus needing the energies and the equilibrium geometries of the neutral (e.g., $E_{\mathrm{CPP}}$ ) and ionized (e.g., $\left.E_{\mathrm{CPP}}^{+}\right)$ 
species. These quantities can be safely calculated at the DFT level using a hybrid functional [244, 245]. Additionally, the supramolecular order influences the electronic coupling between neighbouring molecules through the interaction mediated by:

$$
V_{12}=\left\langle\Psi_{1}|\hat{H}| \Psi_{2}\right\rangle
$$

with $\Psi_{j}$ the many-electron wavefunctions for the pair of involved molecules. If the excess (or defect) charge occupies the frontier molecular orbitals, HOMO and LUMO for holes and electrons, respectively, the expression takes a simplified form:

$$
V_{12}=\left\langle\phi_{1}^{\mathrm{HOMO}(\mathrm{LUMO})}|\hat{H}| \phi_{2}^{\mathrm{HOMO}(\mathrm{LUMO})}\right\rangle .
$$

However, due to the non-orthonormality of the monomers HOMO or LUMO orbitals, a final projection (i.e., a Lödwin transformation) is needed [246]:

$$
V_{12}=\frac{\tilde{V}_{12}-\frac{1}{2}\left(e_{1}+e_{2}\right) S_{12}}{1-S_{12}^{2}}
$$

with $S_{12}$ the overlap and $e_{1}\left(e_{2}\right)$ the site energies defined as $\left\langle\phi_{1}|\hat{H}| \phi_{1}\right\rangle\left(\left\langle\phi_{f}|\hat{H}| \phi_{f}\right\rangle\right)$. The DFT method is also widely applied to calculate the $V_{12}$ values $[247,248]$. Note that the ratio between these two magnitudes, $\frac{2 V_{12}}{\Lambda}<1$, determines in fact the validity of the hopping-like vs. a band regime transport [249].

With the calculated $\Lambda$ and $V_{12}$ values, one can estimate now the corresponding charge-transfer (or kinetic) rate $\left(k_{C T}\right)$ as:

$$
k_{C T}=\frac{4 \pi^{2}}{h}\left|V_{12}\right|^{2} \frac{1}{\sqrt{4 \pi \Lambda_{s} k_{\mathrm{B}} T}} \sum_{v=0}^{\infty}\left[\frac{S_{\text {eff }}^{v}}{v !} \exp \left(-S_{\text {eff }}\right) \exp \left(\frac{-\left(\Lambda_{s}+v \hbar \omega_{e f f}+\Delta G^{\ominus}\right)^{2}}{4 \Lambda_{s} k_{\mathrm{B}} T}\right)\right],
$$

where $\hbar$ and $k_{B}$ are fundamental constants, and $T$ is the temperature, chosen normally to be $298.15 \mathrm{~K}$. $\Lambda_{s}$ takes into account the effect of the embedding of molecules into a polarizable medium [250] and $\Delta G^{\ominus}$ corresponds to the free energy difference between initial and final states. This Marcus-Levitch-Jortner expression includes a quantum correction to the semi-classical Marcus expression [251,252], considering the quantum nature of the vibrational modes through a single effective $\omega_{\text {eff }}$ contribution for the HuangRhys factor $S_{\text {eff }}$ obtained from the relation $\Lambda=\hbar \omega_{\text {eff }} S_{\text {eff }}$. Finally, the charge-carrier mobilities in absence of the electric field can be obtained from the Einstein-Smoluchowski relation which reads:

$$
\mu=\frac{q D}{k_{B} T},
$$

with $D$ the diffusion coefficient arising from the charge-transfer rate $k_{C T}$ and the distance between interacting molecules. The spectral overlap approach for $k_{C T}$, derived directly from the FermiGolden rule, can also be instead employed [253], allowing thus the comparison between experimental and theoretical results [254]. More general transport models based on surface hopping simulations [255] (treating electronic and vibrational degrees of freedom on a equal footing) or the transient localization model [256] also exists and are appropriate for crystalline systems. The reorganization energies are calculated with the GAUSSIAN 09 quantumchemical package [257], while the electronic couplings are obtained from NWCHEM [258] (version 5.0), ORCA [176] (version 4.0), or GAUSSIAN 09 [257] quantum-chemical packages [258], with the Lödwin transformation done from the latter ouput files using an inhouse script.

\section{$5 \quad$ Optical and photophysical properties}

\subsection{Increasingly longer pristine and modified nCPPs}

UV-Vis photoabsorption spectra, fluorescence peak positions, solvatochromism, fluorescence quantum yields, Stokes shifts, vibronic effects, intersystem crossing rates, etc. and other optical and photophysical properties of CPPs and related compounds have been thoroughly studied along the years [259-267]. 
It is clearly established for CPPs of incresing size that the lowest singlet excited-state $S_{1}$ is formed by a HOMO to LUMO $\left(\pi \rightarrow \pi^{\star}\right)$ transition, and that the lowest absorption energies increase with the number of rings up to saturation. However, another unique feature of these molecules, that is somehow counterintuitive for conjugated organic materials is the size-insensitivity of their recorded experimental UVVis absorption spectra, unlike the fluorescence spectra which blue-shifts for nCPPs of increasing size [268]. This behaviour also contrast with that found for their parent linear compounds. Theoretical studies at the TD-DFT level have significantly contributed from the beginning to understand these optical and photophysical unusual properties. Interestingly, the lowest singlet excited-state $S_{1}$ is optically forbidden, with vanishing or very low oscillator strength values for even or odd systems, respectively, and the next $S_{2}$ and $S_{3}$ excited-states are found degenerate (quasi-degenerate) for even (odd) nanorings and show large oscillator strength values. The calculated (solvated) absorption energies for the $S_{2} \approx S_{3}$ singlet excited-states agree perfectly with the experimental, and nearly-constant, value of $3.67 \mathrm{eV}$ regardless of the size of the systems.

Further studies focused on the excitonic properties of these compounds, allowing to reach the understanding needed for the design optical and photonic materials. As a matter of illustration, recent studies applying methods more sophisticated than TD-DFT [269], have revealed how the peak positions of the photoabsorption spectra remains unchanged with system size due to a cancellation of two effects: exciton binding energy and orbital energy [270]. The gas-phase relaxation dynamics of CPPs has also been studied, helping to rationalize the origin of their fluorescence properties $[271,272]$, intersystem crossing and internal conversion processes [273]. On the other hand, to tune the behaviour of CPPs, several design strategies are followed. For instance, the fluorescence peak positions of $\mathrm{nCPPs}^{2+}$ are red-shifted with increasing ring size, and thus are not longer size-insensitive, reaching the near-infrared region for those with $n>5$ [274]. The introduction of acene units such as naphthalene, (nCPPN), anthracene (nCPPA), and tetracene (nCPPT), leading thus to chiral systems, also breaks the symmetry of pristine CPPs with the lowest singlet excited-state $S_{1}$ being now optically allowed and blue-shifted upon increasing size [275-279]. Generally speaking, the interplay of $\pi$-conjugation, bending (or strain effects), and chirality (or symmetry effects) in fact determines all photophysics of CPP-based systems [280], which can also be fine-tuned with functionalization strategies.

\subsection{Weakly interacting nCPP dimers}

The supramolecular order might lead to excitonic properties differing from those found for isolated conjugated systems [281]. This issue has also been investigated for selected 6CPP dimers representing the crystalline packing [282]. Depending on the relative orientation and distance between the monomers of these weakly interacting dimers, the excited-state energies of isolated molecules $(\Omega)$ are splitted into $\Omega^{\prime}=$ $\Omega \pm \beta$, with $\beta$ the resonance energy given by the coupling between the ground-state (CPP) and excitedstate $\left(\mathrm{CPP}^{\star}\right)$ wavefunctions $\left\langle\Psi_{\mathrm{CPP}} \Psi_{\mathrm{CPP}^{\star}}|\hat{V}| \Psi_{\mathrm{CPP}} \Psi_{\mathrm{CPP}}\right\rangle$, with the results driven by long-range interactions and differing for each excited state. Traditionally, single-reference methods, such as TD-DFT, can not describe the effects giving rise to this kind of excited-states $[283,284]$ and this has motivated the use of more advanced methods or corrections to standard TD-DFT [285]. The tubular-like dimers are characterized by an almost negligible resonance energy $(\beta \approx 0 \mathrm{eV})$ or, in other words, a very weak excitonic coupling typical of long intramolecular distances and poor $\pi-\pi$ overlap. On the other hand, the excitedstate energies of parallel dimers are consistently red-shifted by around $\beta \approx 0.2 \mathrm{eV}$ with respect to that of the isolated monomer, a typical feature of J-type interactions with important consequences for absortion/emission spectra [286,287].

\subsection{Donor-Acceptor systems and TADF applications}

The experimental synthesis of Donor-Acceptor (D-A) compounds [288-290] has propelled the study of the photophysical and semiconducting properties of this set of materials $[112,125,291]$. Figure 7 shows some functionalization strategies of CPPs leading to N-doped systems. An inmediate consequence of the 
D-A fragments introduced is the localization of the HOMO and LUMO on different parts of the molecule, thus poorly overlapping and consequently reducing the HOMO-LUMO energy gap with respect to the undoped CPP systems. This has important consequences on the lowest singlet- and triplet-excited states of these compounds $[125,291]$, and also leads to a relatively low singlet-triplet energy gap $\Delta E_{S T}$, allowing thus to theoretically explore the use of these molecules as Thermally Activated Delayed Fluorescence (TADF) emitters $[292,293]$ : The full harvesting of both singlet and triplet excitons can facilitate light-emission mechanisms beyond the spin statistical limit [294-297] for sufficiently small $\Delta E_{S T}$ values (around $0.1-0.2 \mathrm{eV}$ ). Whereas the 8CPP system has a singlet-triplet gap of $0.5 \mathrm{eV}$ and a forbidden (for symmetry reasons) $S_{1} \leftarrow S_{0}$ transition, thus precluding its use for any intended TADF application, the D-A strategy roughly halves the singlet-triplet gap while keeping non-vanishing oscillator strength values. The use of some metrics to better quantify the spatial orbital separation, as extensively done for TADF applications, agrees with the intermolecular charge-transfer character of the lowest singlet and triplet excited-states of D-A nCPPs.

\subsection{Theoretical methods and computational tools}

The calculation of $S_{1} \leftarrow S_{0}$ and $T_{1} \leftarrow S_{0}$ excitation energies, or in general $S_{n} \leftarrow S_{0}$ and $T_{n} \leftarrow S_{0}$, normally benefits from TD-DFT methods (e.g., range-separated functionals) able to cope with intramolecular charge-transfer excitations, as those arising from the localization of the HOMO and LUMO orbitals on different spatial molecular fragments or monomers [298], and the Tamm-Dancoff approximation [299] to improve the accuracy of the $T_{1} \leftarrow S_{0}$ excitation energy and band shapes [300,301]. The use of doublehybrid density functionals for excited-states [302,303], incorporating a fraction of long-range perturbative correlation effects [304], offers an alternative to robustly describe excitonic effects too. Alternatively, other methods such as Spin-Component-Scaled (SCS-) second-order approximate Coupled Cluster singles and doubles, CC2 [305, 306], and Algebraic Diagrammatic Construction at second-order, $\operatorname{ADC}(2)$ [307], are also expected to behave accurately in challenging photochromic systems $[308,309]$.

Not only the energies, but the whole analysis of electronic excitation processes is a flourishing field [310] independently of the method selected. For instance, if the extent of the hole-particle separation is important, as it happens for TADF or intermolecular excitonic studies, the use of some metrics has revealed as a very useful tool for the rationalization of the results and the quantitative screening of compounds [311]. Among these tools, we describe the spatial hole-electron separation [312,313]:

$$
\Delta r=\frac{\sum_{i a} \kappa_{i a}^{2}\left|\left\langle\phi_{a}|\hat{\mathbf{r}}| \phi_{a}\right\rangle-\left\langle\phi_{i}|\hat{\mathbf{r}}| \phi_{i}\right\rangle\right|}{\sum_{i a} \kappa_{i a}^{2}}
$$

with $\kappa_{i a}$ the coefficients for the $\phi_{i} \rightarrow \phi_{a}$ one-electron (occupied to virtual molecular orbitals) promotion contributing to the $S_{1}$ or $T_{1}$ excited-state. Other employed (complementary) diagnostics could be $D_{C T}$, the spatial distance between the barycenters of density changes associated with an electronic transition [314], or the overlap $\phi_{S}$ between the attachment and dettachment densities [284] created upon the rearrangement of the electronic density for electronic excitations. Independently of the final method selected, the use of Natural Transition Orbitals [315] in excited-state studies is also convenient, to diagonalize the density matrix coupling both $\Psi_{E S}$ and $\Psi_{G S}$ wavefunctions without altering the excitation energies. In such a way, each hole-particle pair created upon excitation can be easily represented even for cases when more than one-electron $\phi_{i} \rightarrow \phi_{a}$ promotion is involved and the description in terms of standard molecular orbitals can be complicated. Finally, for symmetric nanorings, the oscillator strength values are directly proportional to the transition dipole moment, $f \propto\left\langle\Psi_{E S}|\hat{\mu}| \Psi_{G S}\right\rangle$ with $\Psi_{E S}\left(\Psi_{G S}\right)$ the excited-state (ground-state) wavefunctions, we can rationalize the results for even and off CPPs according to molecular symmetry: the direct product $\Gamma\left(\Psi_{G S}\right) \otimes \Gamma(\hat{\mu}) \otimes \Gamma\left(\Psi_{E S}\right)$ should contain the totally symmetric irreducible representation of the $D_{n h}$ point group to which these molecules belong, otherwise $f=0$. All the TD-DFT calculations are performed with the GAUSSIAN 09 [257] or ORCA [176] (version 


\section{0 or higher) quantum-chemical packages, using GABEDIT [316], MULTIWFN [317] and the NANCY-EX $[318,319]$ tools for postprocessing of the results.}

\section{Perspectives}

We have presented here a systematic, and hopefully insightful, revision of recent advances for hoop-shaped applications of organic nanorings of varying composition, shape, and size. These progresses not only show that nanorings can be used as novel materials, but also that their molecular design can be accurately fine-tuned upon the use of state-of-the-art theoretical methods often going beyond the most standard methods employed so far. This highlights the trade-off needed between experiments and theory, exploiting the best of both worlds towards the understanding of the many appealing (and sometimes counterintuitive) properties of these compounds. The structure-property relationships are in fact largely influenced by the interplay between single-molecule and supramolecular properties. While the former depend on the chemical nature and topology of the nanoring, the latter are dominated by the moleculeto-molecule interactions, thus providing a path to derive optimal properties at the mesoscale through a computatioally assited bottom-up approach. The transition from single-molecule to bulk properties first demands the use of accurate methods and models at the quantum-chemical level, to disclose the corresponding physical effects driving the properties tackled. Simulations at the nanoscale (e.g., molecular dynamics simulations) can describe the importance of those specific effects into the collective behaviour, allowing thus to anticipate the performance of the materials designed. Overall, the experimental feedback becomes very useful to benchmark and improve the theoretical methods, closing the loop as the chemical ( $\pi$-conjugated) units also do to create these fascinating nanoforms.

\section{Acknowledgements}

Computational resources were provided along the years by projects CTQ2014-55073-P and PID2019106114GB-I00 ("Ministerio de Ciencia e Innovación") and AICO/2018/175 ("Generalitat Valenciana"). The authors would also like to thank the work of all past and present undergraduate and Ph.D. students (J.V. Climent-Medina, M. Reche-Tamayo, C. Graham, R. Ortiz-Cano, and A. Pérez-Guardiola), as well as colleagues M. Moral-Muñoz (from the University of Castilla - La Mancha, Spain), E. San-Fabián (from the University of Alicante, Spain), M.E. Sandoval-Salinas (from the University of Barcelona, Spain), D. Casanova (from the University of Basque Country, Spain), A. Navarro (from the University of Jaén, Spain), J. Fernández-Rossier (from the Iberian Nanotechnology Laboratory, Portugal), Y. Olivier (from the University of Namur, Belgium), R. Jasti (from the University of Oregon, USA), and S. Canola, F. Negri, and L. Muccioli (from the University of Bologna, Italy) for stimulating discussions along the years around these fascinating systems.

\section{References}

[1] L. T. Scott, Angewandte Chemie International Edition 2003, 42, 354133.

[2] S. E. Lewis, Chemical Society Reviews 2015, 44, 82221.

[3] E. J. Leonhardt, R. Jasti, Nature Reviews Chemistry 2019, 1-15.

[4] Y. Segawa, D. R. Levine, K. Itami, Accounts of chemical research 2019, 52, 102760.

[5] G. M. Peters, G. Grover, R. L. Maust, C. E. Colwell, H. Bates, W. A. Edgell, R. Jasti, M. Kertesz, J. D. Tovar, Journal of the American Chemical Society 2020, 142, 52293.

[6] M. R. Talipov, R. Jasti, R. Rathore, Journal of the American Chemical Society 2015, 137, 47 14999.

[7] R. Jasti, J. Bhattacharjee, J. B. Neaton, C. R. Bertozzi, Journal of the American Chemical Society 2008, 130, 5217646. 
[8] B. D. Steinberg, L. T. Scott, Angewandte Chemie International Edition 2009, 48, 305400.

[9] H. Takaba, H. Omachi, Y. Yamamoto, J. Bouffard, K. Itami, Angewandte Chemie International Edition 2009, 48, 336112.

[10] D. Eisenberg, R. Shenhar, M. Rabinovitz, Chemical Society Reviews 2010, 39, 82879.

[11] H. Omachi, S. Matsuura, Y. Segawa, K. Itami, Angewandte Chemie International Edition 2010, 49, 5210202 .

[12] S. Yamago, Y. Watanabe, T. Iwamoto, Angewandte Chemie International Edition 2010, $49,4757$.

[13] Y. Ishii, Y. Nakanishi, H. Omachi, S. Matsuura, K. Matsui, H. Shinohara, Y. Segawa, K. Itami, Chemical Science 2012, 3, 72340.

[14] U. H. Bunz, S. Menning, N. Martín, Angewandte Chemie International Edition 2012, 51, 297094.

[15] E. S. Hirst, R. Jasti, The Journal of Organic Chemistry 2012, 77, 2310473.

[16] J. Xia, M. R. Golder, M. E. Foster, B. M. Wong, R. Jasti, Journal of the American Chemical Society 2012, 134, 4819709.

[17] E. Kayahara, Y. Sakamoto, T. Suzuki, S. Yamago, Organic Letters 2012, 14, 133284.

[18] E. R. Darzi, T. J. Sisto, R. Jasti, The Journal of Organic Chemistry 2012, 7r, 156624.

[19] T. J. Sisto, R. Jasti, Synlett 2012, 2012, 04483.

[20] H. Omachi, Y. Segawa, K. Itami, Accounts of Chemical Research 2012, 45, 81378.

[21] S. Yamago, E. Kayahara, T. Iwamoto, The Chemical Record 2014, 14, 184.

[22] E. Kayahara, V. K. Patel, S. Yamago, Journal of the American Chemical Society 2014, 136, 6 2284.

[23] P. J. Evans, E. R. Darzi, R. Jasti, Nature Chemistry 2014, 6, 5404.

[24] Y. Segawa, T. Kuwabara, K. Matsui, S. Kawai, K. Itami, Tetrahedron 2015, 71, 26-27 4500.

[25] E. Kayahara, V. K. Patel, J. Xia, R. Jasti, S. Yamago, Synlett 2015, 26, 111615.

[26] M. R. Golder, R. Jasti, Accounts of Chemical Research 2015, 48, 3557.

[27] N. K. Mitra, R. Meudom, J. D. Gorden, B. L. Merner, Organic Letters 2015, 17, 112700.

[28] H. Kim, H.-J. Lee, D.-P. Kim, Angewandte Chemie International Edition 2016, 55, 41422.

[29] B. Farajidizaji, C. Huang, H. Thakellapalli, S. Li, N. G. Akhmedov, B. V. Popp, J. L. Petersen, K. K. Wang, The Journal of Organic Chemistry 2017, 82, 84458.

[30] C. Huang, S. Li, H. Thakellapalli, B. Farajidizaji, Y. Huang, N. G. Akhmedov, B. V. Popp, J. L. Petersen, K. K. Wang, The Journal of organic chemistry 2017, 82, 21166.

[31] D. Wu, W. Cheng, X. Ban, J. Xia, Asian Journal of Organic Chemistry 2018, 7, 112161.

[32] M. A. Majewski, M. Stepień, Angewandte Chemie International Edition 2019, 58, 186.

[33] S. Yamago, E. Kayahara, Journal of Synthetic Organic Chemistry, Japan 2019, 77, 111147.

[34] T. Kawanishi, K. Ishida, E. Kayahara, S. Yamago, The Journal of Organic Chemistry 2020, 85, 4 2082.

[35] A. V. Zabula, A. S. Filatov, J. Xia, R. Jasti, M. A. Petrukhina, Angewandte Chemie International Edition 2013, 52, 195033. 
[36] M. R. Golder, B. M. Wong, R. Jasti, Chemical Science 2013, 4, 114285.

[37] M. Fujitsuka, S. Tojo, T. Iwamoto, E. Kayahara, S. Yamago, T. Majima, The Journal of Physical Chemistry Letters 2014, 5, 132302.

[38] N. Toriumi, A. Muranaka, E. Kayahara, S. Yamago, M. Uchiyama, Journal of the American Chemical Society 2014, 137, 182.

[39] E. Kayahara, T. Kouyama, T. Kato, S. Yamago, Journal of the American Chemical Society 2016, 138, 1338.

[40] E. Kayahara, K. Fukayama, T. Nishinaga, S. Yamago, Chemistry-An Asian Journal 2016, 11, 12 1793.

[41] S. N. Spisak, Z. Wei, E. Darzi, R. Jasti, M. A. Petrukhina, Chemical Communications 2018, 54, 567818.

[42] A. Stergiou, J. Rio, J. H. Griwatz, D. Arčon, H. A. Wegner, C. P. Ewels, N. Tagmatarchis, Angewandte Chemie 2019, 131, 4917909.

[43] T. Iwamoto, Y. Watanabe, Y. Sakamoto, T. Suzuki, S. Yamago, Journal of the American Chemical Society 2011, 133, 218354.

[44] E. R. Darzi, R. Jasti, Chemical Society Reviews 2015, 44, 186401.

[45] S. Kigure, S. Okada, Japanese Journal of Applied Physics 2014, 53, 6S 06JD06.

[46] M. P. Álvarez, P. M. Burrezo, T. Iwamoto, L. Qiu, M. Kertesz, M. Taravillo, V. G. Baonza, J. T. L. Navarrete, S. Yamago, J. Casado, Faraday Discussions 2014, 173157.

[47] H. Ueno, T. Nishihara, Y. Segawa, K. Itami, Angewandte Chemie International Edition 2015, 54, 123707.

[48] J. Rio, D. Erbahar, M. Rayson, P. Briddon, C. Ewels, Physical Chemistry Chemical Physics 2016, 18, 3323257.

[49] J. Rio, S. Beeck, G. Rotas, S. Ahles, D. Jacquemin, N. Tagmatarchis, C. Ewels, H. A. Wegner, Angewandte Chemie International Edition 2018, 57, 236930.

[50] Y. Xu, R. Kaur, B. Wang, M. B. Minameyer, S. Gsänger, B. Meyer, T. Drewello, D. M. Guldi, M. von Delius, Journal of the American Chemical Society 2018, 140, 4113413.

[51] B. M. White, Y. Zhao, T. E. Kawashima, B. P. Branchaud, M. D. Pluth, R. Jasti, ACS Central Science 2018, 4, 91173.

[52] Á. V. Vidal, C. S. López, O. N. Faza, Physical Chemistry Chemical Physics 2018, $20,138607$.

[53] T. Iwamoto, Y. Watanabe, H. Takaya, T. Haino, N. Yasuda, S. Yamago, Chemistry-A European Journal 2013, 19, 4214061.

[54] T. Iwamoto, Z. Slanina, N. Mizorogi, J. Guo, T. Akasaka, S. Nagase, H. Takaya, N. Yasuda, T. Kato, S. Yamago, Chemistry-A European Journal 2014, 20, 4414403.

[55] C. Zhao, H. Meng, M. Nie, X. Wang, Z. Cai, T. Chen, D. Wang, C. Wang, T. Wang, The Journal of Physical Chemistry C 2019, 123, 1912514.

[56] W. Zhang, A. Abdulkarim, F. E. Golling, H. J. Räder, K. Müllen, Angewandte Chemie 2017, 129, 102689.

[57] A. Joshi, C. Ramachandran, The Journal of Physical Chemistry C 2018, 122, 3419904. 
[58] J. M. Van Raden, R. Jasti, Science 2019, 365, 6450216.

[59] J. M. Van Raden, B. M. White, L. N. Zakharov, R. Jasti, Angewandte Chemie International Edition 2019, 58, 227341.

[60] M. Barrejón, A. Mateo-Alonso, M. Prato, European Journal of Organic Chemistry 2019, 2019, 21 3371.

[61] L. Qiu, M. Peña-Álvarez, M. Taravillo, P. J. Evans, E. R. Darzi, R. Jasti, P. M. Burrezo, J. T. Lopez Navarrete, V. G. Baonza, J. Casado, et al., Chemistry-A European Journal 2017, 23, 65 16593.

[62] K. Senthilkumar, M. Kondratowicz, T. Lis, P. J. Chmielewski, J. Cybinska, J. L. Zafra, J. Casado, T. Vives, J. Crassous, L. Favereau, et al., Journal of the American Chemical Society 2019, 141, 18 7421.

[63] L.-j. Gong, C. Ma, W.-f. Lin, J.-k. Lv, X.-y. Zhang, RSC Advances 2020, 10, 2413984.

[64] S. Martín-Santamaría, H. S. Rzepa, Journal of the Chemical Society, Perkin Transactions 22000, , 122378 .

[65] S. Nishigaki, Y. Shibata, A. Nakajima, H. Okajima, Y. Masumoto, T. Osawa, A. Muranaka, H. Sugiyama, A. Horikawa, H. Uekusa, et al., Journal of the American Chemical Society 2019, 141,3814955 .

[66] J. B. Lin, E. R. Darzi, R. Jasti, I. Yavuz, K. Houk, Journal of the American Chemical Society 2019, 141, 2952.

[67] B. N. Taber, C. F. Gervasi, J. M. Mills, D. A. Kislitsyn, E. R. Darzi, W. G. Crowley, R. Jasti, G. V. Nazin, The Journal of Physical Chemistry Letters 2016, 7, 163073.

[68] K. Itami, Pure and Applied Chemistry 2012, 84, 4907.

[69] S. Hitosugi, T. Yamasaki, H. Isobe, Journal of the American Chemical Society 2012, 134, 30 12442.

[70] H. Omachi, T. Nakayama, E. Takahashi, Y. Segawa, K. Itami, Nature Chemistry 2013, $5,7572$.

[71] T. J. Sisto, L. N. Zakharov, B. M. White, R. Jasti, Chemical Science 2016, 7, 63681.

[72] D.-e. Jiang, X.-Q. Chen, W. Luo, W. A. Shelton, Chemical Physics Letters 2009, 483, 1-3 120.

[73] S. M. Bachrach, D. Stück, The Journal of Organic Chemistry 2010, 75, 196595.

[74] D. Sadowsky, K. McNeill, C. J. Cramer, Faraday Discussions 2010, 145507.

[75] Y. Segawa, H. Omachi, K. Itami, Organic Letters 2010, 12, 102262.

[76] S. Taubert, D. Sundholm, F. Pichierri, The Journal of Organic Chemistry 2010, 75, 175867.

[77] L. Türker, S. Gümüş, Journal of Molecular Structure: THEOCHEM 2004, 685, 1-3 1.

[78] Y. Kameoka, T. Sato, T. Koyama, K. Tanaka, T. Kato, Chemical Physics Letters 2014, 59869.

[79] J.-V. Climent-Medina, Á.-J. Pérez-Jiménez, M. Moral, E. San-Fabián, J.-C. Sancho-García, ChemPhysChem 2015, 16, 71520.

[80] H. Chen, M. R. Golder, F. Wang, S. K. Doorn, R. Jasti, S. Tretiak, A. K. Swan, The Journal of Physical Chemistry C 2015, 119, 52879.

[81] J. Liu, L. Adamska, S. K. Doorn, S. Tretiak, Physical Chemistry Chemical Physics 2015, 17, 22 14613. 
[82] Y. Segawa, A. Yagi, H. Ito, K. Itami, Organic Letters 2016, 18, 61430.

[83] M. Fujitsuka, E. Kayahara, C. Lu, S. Yamago, T. Majima, Physical Chemistry Chemical Physics 2018, 20, 4629207.

[84] A. Muñoz-Castro, Physical Chemistry Chemical Physics 2018, 20, 53433.

[85] E. H. Fort, P. M. Donovan, L. T. Scott, Journal of the American Chemical Society 2009, 131, 44 16006.

[86] E. H. Fort, L. T. Scott, Journal of Materials Chemistry 2011, 21, 51373.

[87] H.-B. Li, A. J. Page, S. Irle, K. Morokuma, ChemPhysChem 2012, 13, 61479.

[88] P. Li, B. M. Wong, L. N. Zakharov, R. Jasti, Organic Letters 2016, 18, 71574.

[89] E. P. Jackson, T. J. Sisto, E. R. Darzi, R. Jasti, Tetrahedron 2016, 72, 263754.

[90] J.-S. Dang, W.-W. Wang, X. Zhao, S. Nagase, Organic Chemistry Frontiers 2017, 4, 91757.

[91] M. Reche-Tamayo, A. Pérez-Guardiola, Á. J. Pérez-Jiménez, J.-C. Sancho-García, Chemical Physics Letters 2018, 69717.

[92] T. A. Schaub, J. T. Margraf, L. Zakharov, K. Reuter, R. Jasti, Angewandte Chemie International Edition 2018, 57, 5016348.

[93] I. G. Cuesta, T. Pedersen, H. Koch, A. Sánchez de Meras, ChemPhysChem 2006, 7, 122503.

[94] K. Yuan, Y.-J. Guo, T. Yang, J.-S. Dang, P. Zhao, Q.-Z. Li, X. Zhao, Journal of Physical Organic Chemistry 2014, 27, 10772.

[95] K. Yuan, C.-H. Zhou, Y.-C. Zhu, X. Zhao, Physical Chemistry Chemical Physics 2015, 17, 28 18802.

[96] J. Antony, R. Sure, S. Grimme, Chemical Communications 2015, 51, 101764.

[97] S. M. Bachrach, Z.-C. Zayat, The Journal of Organic Chemistry 2016, 81, 114559.

[98] S. Hashimoto, T. Iwamoto, D. Kurachi, E. Kayahara, S. Yamago, ChemPlusChem 2017, 82, 7 1015.

[99] P. Della Sala, C. Talotta, A. Capobianco, A. Soriente, M. De Rosa, P. Neri, C. Gaeta, Organic Letters 2018, 20, 237415.

[100] K. Miki, K. Saiki, T. Umeyama, J. Baek, T. Noda, H. Imahori, Y. Sato, K. Suenaga, K. Ohe, Small 2018, 14, 261800720.

[101] I. González-Veloso, J. Rodríguez-Otero, E. M. Cabaleiro-Lago, Physical Chemistry Chemical Physics 2019, 21, 3016665.

[102] I. González-Veloso, J. Rodríguez-Otero, E. M. Cabaleiro-Lago, Structural Chemistry 2019, 30, 3 647.

[103] R. Gleiter, B. Esser, S. C. Kornmayer, Accounts of Chemical Research 2009, 42, 81108.

[104] A. Pérez-Guardiola, M. E. Sandoval-Salinas, D. Casanova, E. San-Fabián, Á. J. Pérez-Jiménez, J.C. Sancho-García, Physical Chemistry Chemical Physics 2018, 20, 107112.

[105] H. S. Choi, K. S. Kim, Angewandte Chemie International Edition 1999, 38, 152256.

[106] A. Pérez-Guardiola, R. Ortiz-Cano, M. E. Sandoval-Salinas, J. Fernández-Rossier, D. Casanova, Á. J. Pérez-Jiménez, J.-C. Sancho-García, Physical Chemistry Chemical Physics 2019, 21, 52547. 
[107] M. Reche-Tamayo, M. Moral, A. J. Pérez-Jiménez, J. C. Sancho-García, The Journal of Physical Chemistry C 2016, 120, 3922627.

[108] Y. Ishii, S. Matsuura, Y. Segawa, K. Itami, Organic Letters 2014, 16, 82174.

[109] E. Kayahara, R. Qu, S. Yamago, Angewandte Chemie International Edition 2017, 56, 3510428.

[110] S. Hashimoto, E. Kayahara, Y. Mizuhata, N. Tokitoh, K. Takeuchi, F. Ozawa, S. Yamago, Organic Letters 2018, 20, 185973.

[111] J.-C. Sancho-García, M. Moral, A. Pérez-Jiménez, The Journal of Physical Chemistry C 2016, 120, 179104 .

[112] S. Canola, C. Graham, Á. J. Pérez-Jiménez, J.-C. Sancho-García, F. Negri, Physical Chemistry Chemical Physics 2019, 21, 42057.

[113] E. Nakamura, K. Tahara, Y. Matsuo, M. Sawamura, Journal of the American Chemical Society 2003, 125, 102834.

[114] A. Yagi, Y. Segawa, K. Itami, Journal of the American Chemical Society 2012, 134, 62962.

[115] C. Huang, Y. Huang, N. G. Akhmedov, B. V. Popp, J. L. Petersen, K. K. Wang, Organic Letters 2014, 16, 102672.

[116] N. Hayase, Y. Miyauchi, Y. Aida, H. Sugiyama, H. Uekusa, Y. Shibata, K. Tanaka, Organic Letters 2017, 19, 112993.

[117] S. Li, M. Aljhdli, H. Thakellapalli, B. Farajidizaji, Y. Zhang, N. G. Akhmedov, C. Milsmann, B. V. Popp, K. K. Wang, Organic Letters 2017, 19, 154078.

[118] D. Lu, G. Zhuang, H. Jia, J. Wang, Q. Huang, S. Cui, P. Du, Organic Chemistry Frontiers 2018, 5, 91446 .

[119] S. Cui, G. Zhuang, J. Wang, Q. Huang, S. Wang, P. Du, Organic Chemistry Frontiers 2019, 6, 11 1885 .

[120] N. Hayase, H. Sugiyama, H. Uekusa, Y. Shibata, K. Tanaka, Organic Letters 2019, $21,113895$.

[121] H. Zhao, Y.-C. Ma, L. Cao, S. Huang, J.-P. Zhang, X. Yan, The Journal of Organic Chemistry 2019, 84, 95230 .

[122] T. Kuwabara, J. Orii, Y. Segawa, K. Itami, Angewandte Chemie International Edition 2015, 54, 339646 .

[123] J. Van Raden, E. Darzi, L. Zakharov, R. Jasti, Organic \& Biomolecular Chemistry 2016, 14, 24 5721.

[124] S. Nishigaki, M. Fukui, H. Sugiyama, H. Uekusa, S. Kawauchi, Y. Shibata, K. Tanaka, ChemistryA European Journal 2017, 23, 307227.

[125] C. Graham, M. Moral, L. Muccioli, Y. Olivier, Á. J. Pérez-Jiménez, J.-C. Sancho-García, International Journal of Quantum Chemistry 2018, 118, 12 e25562.

[126] T. Matsuno, S. Kamata, S. Hitosugi, H. Isobe, Chemical Science 2013, 4, 83179.

[127] T. Iwamoto, E. Kayahara, N. Yasuda, T. Suzuki, S. Yamago, Angewandte Chemie International Edition 2014, 53, 256430.

[128] A. Yagi, G. Venkataramana, Y. Segawa, K. Itami, Chemical Communications 2014, 50, 8957.

[129] M. Fujitsuka, S. Tojo, T. Iwamoto, E. Kayahara, S. Yamago, T. Majima, The Journal of Physical Chemistry A 2015, 119, 184136. 
[130] M. Moral, A. Pérez-Guardiola, E. San-Fabián, A. Pérez-Jiménez, J.-C. Sancho-García, The Journal of Physical Chemistry C 2016, 120, 3822069.

[131] A. Pérez-Guardiola, Á. J. Pérez-Jiménez, J.-C. Sancho-García, Molecular Systems Design E Engineering 2017, 2, 3253.

[132] A. Pérez-Guardiola, Á. J. Pérez-Jiménez, L. Muccioli, J. C. Sancho-García, Advanced Materials Interfaces 2019, 6, 81801948.

[133] Z. Chen, D.-e. Jiang, X. Lu, H. F. Bettinger, S. Dai, P. v. R. Schleyer, K. N. Houk, Organic Letters 2007, 9, 265449.

[134] S. Mondal, B. Mandal, Molecular Physics 2019, 1-15.

[135] D. Casanova, M. Head-Gordon, Physical Chemistry Chemical Physics 2009, 11, 429779.

[136] S. Grimme, A. Hansen, Angewandte Chemie International Edition 2015, 54, 4212308.

[137] C. A. Bauer, A. Hansen, S. Grimme, Chemistry-A European Journal 2017, 23, 256150.

[138] E. S. Hirst, F. Wang, R. Jasti, Organic Letters 2011, 13, 236220.

[139] B. Esser, J. A. Raskatov, R. Gleiter, Organic Letters 2007, 9, 204037.

[140] B. Esser, F. Rominger, R. Gleiter, Journal of the American Chemical Society 2008, $130,216716$.

[141] B. Esser, A. Bandyopadhyay, F. Rominger, R. Gleiter, Chemistry-A European Journal 2009, 15, 143368.

[142] A. O. Ortolan, N. D. Charistos, R. Guajardo-Maturana, C. O. Ulloa, G. F. Caramori, R. L. Parreira, A. Muñoz-Castro, International Journal of Quantum Chemistry 2019, 119, 4 e25811.

[143] B. Esser, Physical Chemistry Chemical Physics 2015, 17, 117366.

[144] L. Türker, S. Gümüs, Journal of Molecular Structure: THEOCHEM 2004, 679, 3143.

[145] M. Kassaee, H. A. Rad, S. S. Amiri, Monatshefte für Chemie-Chemical Monthly 2010, 141,12 1313.

[146] M. Kassaee, H. Zandi, H. A. Rad, M. Ghambarian, Monatshefte für Chemie-Chemical Monthly 2013, 144, 121783.

[147] M. Koohi, M. Ghavami, B. N. Haerizade, H. Zandi, M. Z. Kassaee, Journal of Physical Organic Chemistry 2014, 27, 9735.

[148] G. Povie, Y. Segawa, T. Nishihara, Y. Miyauchi, K. Itami, Science 2017, 356, 6334172.

[149] H. A. Wegner, Angewandte Chemie International Edition 2017, 56, 3710995.

[150] G. Povie, Y. Segawa, T. Nishihara, Y. Miyauchi, K. Itami, Journal of the American Chemical Society 2018, 140, 3110054 .

[151] T.-H. Shi, Q.-H. Guo, S. Tong, M.-X. Wang, Journal of the American Chemical Society 2020, 142, 104576.

[152] Y. Qiu, H. Chen, Y. Feng, M. E. Schott, J. F. Stoddart, Chem 2020, 6, 4826.

[153] F. Schulz, F. García, K. Kaiser, D. Pérez, E. Guitián, L. Gross, D. Peña, Angewandte Chemie 2019, 131, 279136.

[154] T. J. Sisto, X. Tian, R. Jasti, The Journal of Organic Chemistry 2012, 77, 145857. 
[155] F. E. Golling, S. Osella, M. Quernheim, M. Wagner, D. Beljonne, K. Müllen, Chemical Science 2015, 6, 127072.

[156] D. Lu, H. Wu, Y. Dai, H. Shi, X. Shao, S. Yang, J. Yang, P. Du, Chemical Communications 2016, 52, 447164 .

[157] R. Jasti, C. R. Bertozzi, Chemical Physics Letters 2010, 494, 1-3 1.

[158] C. E. Colwell, T. W. Price, T. Stauch, R. Jasti, Chemical Science 2020, 11, 153923.

[159] S. Battaglia, H.-A. Le, G. L. Bendazzoli, N. Faginas-Lago, T. Leininger, S. Evangelisti, International Journal of Quantum Chemistry 2018, 118, 12 e25569.

[160] H. C. Longuet-Higgins, L. Salem, Proceedings of the Royal Society of London. Series A. Mathematical and Physical Sciences 1960, 257, 1291445.

[161] E. Heilbronner, Tetrahedron Letters 1964, 5, 291923.

[162] R. Ortiz, R. A. Boto, N. García-Martínez, J. C. Sancho-García, M. Melle-Franco, J. FernándezRossier, Nano Letters 2019, 19, 95991.

[163] B. Hajgató, M. S. Deleuze, Chemical Physics Letters 2012, 5536.

[164] F. Illas, I. P. Moreira, C. De Graaf, V. Barone, Theoretical Chemistry Accounts 2000, 104, 3-4 265.

[165] D. H. Ess, E. R. Johnson, X. Hu, W. Yang, The Journal of Physical Chemistry A 2010, $115,176$.

[166] A. Das, T. Muller, F. Plasser, H. Lischka, The Journal of Physical Chemistry A 2016, 120, 91625.

[167] J.-D. Chai, The Journal of Chemical Physics 2012, 136, 15154104.

[168] J.-D. Chai, The Journal of Chemical Physics 2014, 140, 18 18A521.

[169] C.-Y. Lin, K. Hui, J.-H. Chung, J.-D. Chai, RSC Advances 2017, 7, 8050496.

[170] C.-S. Wu, P.-Y. Lee, J.-D. Chai, Scientific Reports 2016, 6, 11.

[171] S. Battaglia, N. Faginas-Lago, D. Andrae, S. Evangelisti, T. Leininger, The Journal of Physical Chemistry A 2017, 121, 193746.

[172] X. Lu, S. Lee, Y. Hong, H. Phan, T. Y. Gopalakrishna, T. S. Herng, T. Tanaka, M. E. SandovalSalinas, W. Zeng, J. Ding, D. Casanova, A. Osuka, D. Kim, J. Wu, Journal of the American Chemical Society 2017, 139, 3713173.

[173] C. Liu, M. E. Sandoval-Salinas, Y. Hong, T. Y. Gopalakrishna, H. Phan, N. Aratani, T. S. Herng, J. Ding, H. Yamada, D. Kim, D. Casanova, J. Wu, Chem 2018, 4, 71586.

[174] Z. Li, T. Y. Gopalakrishna, Y. Han, Y. Gu, L. Yuan, W. Zeng, D. Casanova, J. Wu, Journal of the American Chemical Society 2019, 14116266.

[175] Y. Ni, M. E. Sandoval-Salinas, T. Tanaka, H. Phan, T. S. Herng, T. Y. Gopalakrishna, J. Ding, A. Osuka, D. Casanova, J. Wu, Chem 2019, 5, 1108.

[176] F. Neese, Wiley Interdisciplinary Reviews: Computational Molecular Science 2012, 2, 173.

[177] E. F. Pettersen, T. D. Goddard, C. C. Huang, G. S. Couch, D. M. Greenblatt, E. C. Meng, T. E. Ferrin, Journal of Computational Chemistry 2004, 25, 131605.

[178] H. Sakamoto, T. Fujimori, X. Li, K. Kaneko, K. Kan, N. Ozaki, Y. Hijikata, S. Irle, K. Itami, Chemical Ccience 2016, 7, 74204. 
[179] J. Zheng, X. Ren, J. Hao, A. Li, W. Liu, Applied Surface Science 2017, 39360.

[180] T. Fukushima, H. Sakamoto, K. Tanaka, Y. Hijikata, S. Irle, K. Itami, Chemistry Letters 2017, 46, 6855.

[181] J. Zhang, Computational Materials Science 2019, 16896.

[182] Y. Segawa, S. Miyamoto, H. Omachi, S. Matsuura, P. Šenel, T. Sasamori, N. Tokitoh, K. Itami, Angewandte Chemie International Edition 2011, 50, 143244.

[183] J. Xia, R. Jasti, Angewandte Chemie International Edition 2012, 51, 102474.

[184] W. B. Schweizer, J. D. Dunitz, Journal of Chemical Theory and Computation 2006, 2, 2288.

[185] A. L. Ringer, C. D. Sherrill, Chemistry-A European Journal 2008, 14, 82542.

[186] G. J. Beran, K. Nanda, The Journal of Physical Chemistry Letters 2010, 1, 243480.

[187] E. J. Leonhardt, J. M. Van Raden, D. Miller, L. N. Zakharov, B. Alemán, R. Jasti, Nano Letters 2018, 18, 127991.

[188] J. M. Van Raden, E. J. Leonhardt, L. N. Zakharov, A. Pérez-Guardiola, A. Pérez-Jiménez, C. R. Marshall, C. K. Brozek, J.-C. Sancho-García, R. Jasti, The Journal of Organic Chemistry 2020, 85,1129 .

[189] Y. Xu, M. von Delius, Angewandte Chemie International Edition 2020, 59, 2559.

[190] T. Iwamoto, Y. Watanabe, T. Sadahiro, T. Haino, S. Yamago, Angewandte Chemie International Edition 2011, 50, 368342.

[191] K. Yuan, Y.-J. Guo, X. Zhao, The Journal of Physical Chemistry C 2015, 119, 95168.

[192] O. Vostrowsky, A. Hirsch, Angewandte Chemie International Edition 2004, 43, 182326.

[193] S. Grimme, Wiley Interdisciplinary Reviews: Computational Molecular Science 2011, 1, 2211.

[194] J. F. Dobson, T. Gould, Journal of Physics: Condensed Matter 2012, 24, 7073201.

[195] J. Klimeš, A. Michaelides, The Journal of Chemical Physics 2012, 137, 12120901.

[196] S. Grimme, J. Antony, S. Ehrlich, H. Krieg, The Journal of Chemical Physics 2010, 132, 15 154104.

[197] S. Grimme, S. Ehrlich, L. Goerigk, Journal of Computational Chemistry 2011, 32, 71456.

[198] E. Caldeweyher, S. Ehlert, A. Hansen, H. Neugebauer, S. Spicher, C. Bannwarth, S. Grimme, The Journal of Chemical Physics 2019, 150, 15154122.

[199] O. A. Vydrov, T. Van Voorhis, The Journal of Chemical Physics 2010, 133, 24244103.

[200] J. Calbo, E. Ortí, J. C. Sancho-García, J. Aragó, In Annual Reports in Computational Chemistry, volume 11, 37-102. Elsevier, 2015.

[201] W. Hujo, S. Grimme, Journal of Chemical Theory and Computation 2011, 7, 123866.

[202] W. Hujo, S. Grimme, Journal of Chemical Theory and Computation 2013, 9, 1308.

[203] J. Aragó, E. Ortí, J. C. Sancho-García, Journal of Chemical Theory and Computation 2013, 9, 8 3437.

[204] J. Sancho-García, Y. Olivier, The Journal of Chemical Physics 2012, 137, 19194311. 
[205] J.-C. Sancho-Garíca, A. Pérez-Jiménez, Y. Olivier, The Journal of Chemical Physics 2015, 142, 5 054702 .

[206] J. Hermann, R. A. DiStasio Jr, A. Tkatchenko, Chemical Reviews 2017, 117, 64714.

[207] O. Anatole von Lilienfeld, A. Tkatchenko, The Journal of Chemical Physics 2010, 132, 23234109.

[208] M. R. Kennedy, A. R. McDonald, A. E. DePrince III, M. S. Marshall, R. Podeszwa, C. D. Sherrill, Journal of Chemical Physics 2014, 140, 12121104.

[209] R. Sure, S. Grimme, Journal of Computational Chemistry 2013, 34, 191672.

[210] J. G. Brandenburg, C. Bannwarth, A. Hansen, S. Grimme, The Journal of Chemical Physics 2018, 148,6064104 .

[211] J. G. Brandenburg, S. Grimme, Acta Crystallographica Section B: Structural Science, Crystal Engineering and Materials 2016, 72, 4502.

[212] M. Wahiduzzaman, A. F. Oliveira, P. Philipsen, L. Zhechkov, E. van Lenthe, H. A. Witek, T. Heine, Journal of Chemical Theory and Computation 2013, 9, 94006.

[213] J. G. Brandenburg, S. Grimme, The Journal of Physical Chemistry Letters 2014, 5, 111785.

[214] X. Gonze, B. Amadon, P.-M. Anglade, J.-M. Beuken, F. Bottin, P. Boulanger, F. Bruneval, D. Caliste, R. Caracas, M. Côté, et al., Computer Physics Communications 2009, 180, 122582.

[215] X. Gonze, F. Jollet, F. A. Araujo, D. Adams, B. Amadon, T. Applencourt, C. Audouze, J.-M. Beuken, J. Bieder, A. Bokhanchuk, et al., Computer Physics Communications 2016, 205106.

[216] C. F. Macrae, I. J. Bruno, J. A. Chisholm, P. R. Edgington, P. McCabe, E. Pidcock, L. RodriguezMonge, R. Taylor, J. Streek, P. A. Wood, Journal of Applied Crystallography 2008, 41, 2466.

[217] M. Moral, W.-J. Son, J.-C. Sancho-García, Y. Olivier, L. Muccioli, Journal of Chemical Theory and Computation 2015, 11, 73383.

[218] J. C. Phillips, R. Braun, W. Wang, J. Gumbart, E. Tajkhorshid, E. Villa, C. Chipot, R. D. Skeel, L. Kale, K. Schulten, Journal of Computational Chemistry 2005, 26, 161781.

[219] W. Humphrey, A. Dalke, K. Schulten, et al., Journal of Molecular Graphics 1996, 14, 133.

[220] Y. Olivier, V. Lemaur, J.-L. Brédas, J. Cornil, The Journal of Physical Chemistry A 2006, 110, 19 6356.

[221] V. Coropceanu, J. Cornil, D. A. da Silva Filho, Y. Olivier, R. Silbey, J.-L. Brédas, Chemical Reviews 2007, 107, 4926.

[222] M. Mas-Torrent, C. Rovira, Chemical Reviews 2011, 111, 84833.

[223] G. Nan, X. Yang, L. Wang, Z. Shuai, Y. Zhao, Physical Review B 2009, 79, 11115203.

[224] M. Moral, A. Pérez-Jiménez, J.-C. Sancho-García, The Journal of Physical Chemistry C 2017, 121, 63171.

[225] A. Troisi, G. Orlandi, The Journal of Physical Chemistry A 2006, 110, 114065.

[226] N. G. Martinelli, Y. Olivier, S. Athanasopoulos, M.-C. Ruiz Delgado, K. R. Pigg, D. A. da Silva Filho, R. S. Sánchez-Carrera, E. Venuti, R. G. Della Valle, J.-L. Brédas, et al., ChemPhysChem 2009, 10, 132265.

[227] M. Moral, A. Navarro, A. Pérez-Jiménez, J.-C. Sancho-Garcia, The Journal of Physical Chemistry A 2020, 124, 183555. 
[228] J.-L. Brédas, J. P. Calbert, D. da Silva Filho, J. Cornil, Proceedings of the National Academy of Sciences 2002, 99, 95804.

[229] L. Hu, Y. Guo, X. Yan, H. Zeng, J. Zhou, Physics Letters A 2017, 381, 25-26 2107.

[230] Y.-D. Guo, H.-L. Zeng, L.-Z. Hu, X.-H. Yan, X.-Y. Mou, M.-S. Yang, Physics Letters A 2018, 382, 382763.

[231] J. Mun, J. Kang, Y. Zheng, S. Luo, H.-C. Wu, N. Matsuhisa, J. Xu, G.-J. N. Wang, Y. Yun, G. Xue, et al., Advanced Materials 2019, 31, 421903912.

[232] F. Lucas, L. Sicard, O. Jeannin, J. Rault-Berthelot, E. Jacques, C. Quinton, C. Poriel, ChemistryA European Journal 2019, 25, 327740.

[233] E. Kayahara, L. Sun, H. Onishi, K. Suzuki, T. Fukushima, A. Sawada, H. Kaji, S. Yamago, Journal of the American Chemical Society 2017, 139, 5118480.

[234] H. Chen, M. R. Golder, F. Wang, R. Jasti, A. K. Swan, Carbon 2014, 67203.

[235] M. P. Álvarez, M. C. R. Delgado, M. Taravillo, V. G. Baonza, J. T. L. Navarrete, P. Evans, R. Jasti, S. Yamago, M. Kertesz, J. Casado, Chemical Science 2016, 7, 63494.

[236] M. P. Álvarez, L. Qiu, M. Taravillo, V. G. Baonza, M. C. R. Delgado, S. Yamago, R. Jasti, J. T. L. Navarrete, J. Casado, M. Kertesz, Physical Chemistry Chemical Physics 2016, 18,17 11683.

[237] O. Koçak, I. P. Duru, I. Yavuz, Advanced Theory and Simulations 2019, 2, 51800194.

[238] G. DAvino, L. Muccioli, Y. Olivier, D. Beljonne, The Journal of Physical Chemistry Letters 2016, 7, 3536 .

[239] G. d'Avino, Y. Olivier, L. Muccioli, D. Beljonne, Journal of Materials Chemistry C 2016, 4, 17 3747.

[240] M. Ball, B. Zhang, Y. Zhong, B. Fowler, S. Xiao, F. Ng, M. Steigerwald, C. Nuckolls, Accounts of Chemical Research 2019, 52, 41068.

[241] H. Oberhofer, K. Reuter, J. Blumberger, Chemical Reviews 2017, 117, 1510319.

[242] J.-L. Brédas, D. Beljonne, V. Coropceanu, J. Cornil, Chemical Reviews 2004, 104, 114971.

[243] F. C. Grozema, L. D. Siebbeles, International Reviews in Physical Chemistry 2008, $27,187$.

[244] R. S. Sánchez-Carrera, V. Coropceanu, D. A. da Silva Filho, R. Friedlein, W. Osikowicz, R. Murdey, C. Suess, W. R. Salaneck, J.-L. Brédas, The Journal of Physical Chemistry B 2006, 110, 3818904 .

[245] J. C. Sancho-García, Chemical Physics 2007, 331, 2321.

[246] E. F. Valeev, V. Coropceanu, D. A. da Silva Filho, S. Salman, J.-L. Brédas, Journal of the American Chemical Society 2006, 128, 309882.

[247] J. Huang, M. Kertesz, Chemical Physics Letters 2004, 390, 1-3 110.

[248] C. Sutton, J. S. Sears, V. Coropceanu, J.-L. Bredas, The Journal of Physical Chemistry Letters 2013, 4, 6919 .

[249] I. Yavuz, B. N. Martin, J. Park, K. Houk, Journal of the American Chemical Society 2015, 137, 8 2856.

[250] D. P. McMahon, A. Troisi, ChemPhysChem 2010, 11, 102067. 
[251] R. A. Marcus, Reviews of Modern Physics 1993, 65, 3599.

[252] P. F. Barbara, T. J. Meyer, M. A. Ratner, The Journal of Physical Chemistry 1996, 100,31 13148.

[253] V. Stehr, R. F. Fink, C. Deibel, B. Engels, Journal of Computational Chemistry 2016, 37,23 2146.

[254] V. Stehr, J. Pfister, R. Fink, B. Engels, C. Deibel, Physical Review B 2011, 83, 15155208.

[255] L. Wang, D. Beljonne, The Journal of Physical Chemistry Letters 2013, 4, 111888.

[256] S. Fratini, S. Ciuchi, D. Mayou, G. T. De Laissardière, A. Troisi, Nature Materials 2017, 16, 10 998.

[257] M. J. Frisch, G. W. Trucks, H. B. Schlegel, G. E. Scuseria, M. A. Robb, J. R. Cheeseman, G. Scalmani, V. Barone, B. Mennucci, G. A. Petersson, H. Nakatsuji, M. Caricato, X. Li, H. P. Hratchian, A. F. Izmaylov, J. Bloino, G. Zheng, J. L. Sonnenberg, M. Hada, M. Ehara, K. Toyota, R. Fukuda, J. Hasegawa, M. Ishida, T. Nakajima, Y. Honda, O. Kitao, H. Nakai, T. Vreven, J. A. Montgomery, Jr., J. E. Peralta, F. Ogliaro, M. Bearpark, J. J. Heyd, E. Brothers, K. N. Kudin, V. N. Staroverov, R. Kobayashi, J. Normand, K. Raghavachari, A. Rendell, J. C. Burant, S. S. Iyengar, J. Tomasi, M. Cossi, N. Rega, J. M. Millam, M. Klene, J. E. Knox, J. B. Cross, V. Bakken, C. Adamo, J. Jaramillo, R. Gomperts, R. E. Stratmann, O. Yazyev, A. J. Austin, R. Cammi, C. Pomelli, J. W. Ochterski, R. L. Martin, K. Morokuma, V. G. Zakrzewski, G. A. Voth, P. Salvador, J. J. Dannenberg, S. Dapprich, A. D. Daniels, . Farkas, J. B. Foresman, J. V. Ortiz, J. Cioslowski, D. J. Fox, Gaussian 09 Revision E.01, Gaussian Inc. Wallingford CT 2009.

[258] M. Valiev, E. J. Bylaska, N. Govind, K. Kowalski, T. P. Straatsma, H. J. Van Dam, D. Wang, J. Nieplocha, E. Apra, T. L. Windus, et al., Computer Physics Communications 2010, 181, 9 1477.

[259] B. M. Wong, The Journal of Physical Chemistry C 2009, 113, 5221921.

[260] D. Sundholm, S. Taubert, F. Pichierri, Physical Chemistry Chemical Physics 2010, 12, 112751.

[261] T. J. Sisto, M. R. Golder, E. S. Hirst, R. Jasti, Journal of the American Chemical Society 2011, 133, 4015800 .

[262] T. Nishihara, Y. Segawa, K. Itami, Y. Kanemitsu, The journal of Physical Chemistry Letters 2012, 3, 213125.

[263] Y. Segawa, A. Fukazawa, S. Matsuura, H. Omachi, S. Yamaguchi, S. Irle, K. Itami, Organic E6 Biomolecular Chemistry 2012, 10, 305979.

[264] V. S. Reddy, C. Camacho, J. Xia, R. Jasti, S. Irle, Journal of Chemical Theory and Computation 2014, 10, 94025 .

[265] D. A. Hines, E. R. Darzi, R. Jasti, P. V. Kamat, The Journal of Physical Chemistry A 2014, 118, 91595.

[266] T. Nishihara, Y. Segawa, K. Itami, Y. Kanemitsu, Chemical Science 2014, 5, 62293.

[267] M. Fujitsuka, C. Lu, T. Iwamoto, E. Kayahara, S. Yamago, T. Majima, The Journal of Physical Chemistry A 2014, 118, 254527.

[268] C. Camacho, T. A. Niehaus, K. Itami, S. Irle, Chemical Science 2013, 4, 1187.

[269] X. Blase, I. Duchemin, D. Jacquemin, Chemical Society Reviews 2018, 47, 31022.

[270] Y. Noguchi, O. Sugino, The Journal of Chemical Physics 2017, 146, 14144304. 
[271] L. Stojanovic, S. G. Aziz, R. H. Hilal, F. Plasser, T. A. Niehaus, M. Barbatti, Journal of Chemical Theory and Computation 2017, 13, 125846.

[272] N. Oldani, S. Doorn, S. Tretiak, S. Fernandez-Alberti, Physical Chemistry Chemical Physics 2017, 19, 4530914 .

[273] M. Fujitsuka, C. Lu, B. Zhuang, E. Kayahara, S. Yamago, T. Majima, The Journal of Physical Chemistry A 2019, 123, 224737.

[274] Y. Masumoto, N. Toriumi, A. Muranaka, E. Kayahara, S. Yamago, M. Uchiyama, The Journal of Physical Chemistry A 2018, 122, 235162.

[275] B. M. Wong, J. W. Lee, The Journal of Physical Chemistry Letters 2011, 2, 212702.

[276] R. Franklin-Mergarejo, D. O. Alvarez, S. Tretiak, S. Fernandez-Alberti, Scientific Reports 2016, 6 31253.

[277] R. Daengngern, C. Camacho, N. Kungwan, S. Irle, The Journal of Physical Chemistry A 2018, 122, 377284 .

[278] P. Della Sala, A. Capobianco, T. Caruso, C. Talotta, M. De Rosa, P. Neri, A. Peluso, C. Gaeta, The Journal of organic chemistry 2018, 83, 1220.

[279] J. Wang, G. Zhuang, Q. Huang, Y. Xiao, Y. Zhou, H. Liu, P. Du, Chemical Communications 2019, 55, 649456.

[280] L. Adamska, I. Nayyar, H. Chen, A. K. Swan, N. Oldani, S. Fernandez-Alberti, M. R. Golder, R. Jasti, S. K. Doorn, S. Tretiak, Nano Letters 2014, 14, 116539.

[281] D. Beljonne, J. Cornil, R. Silbey, P. Millié, J. Brédas, The Journal of Chemical Physics 2000, 112, 104749 .

[282] J.-C. Sancho-García, C. Adamo, A. Pérez-Jiménez, Theoretical Chemistry Accounts 2016, 135,1 25.

[283] A. Dreuw, M. Head-Gordon, Journal of the American Chemical Society 2004, 126, 124007.

[284] A. Dreuw, M. Head-Gordon, Chemical Reviews 2005, 105, 114009.

[285] F. D. Meo, P. Trouillas, C. Adamo, J.-C. Sancho-García, The Journal of Chemical Physics 2013, 139, 16164104.

[286] J. Gierschner, S. Y. Park, Journal of Materials Chemistry C 2013, 1, 375818.

[287] J. Gierschner, L. Lüer, B. Milián-Medina, D. Oelkrug, H.-J. Egelhaaf, The Journal of Physical Chemistry Letters 2013, 4, 162686.

[288] K. Matsui, Y. Segawa, K. Itami, Organic Letters 2012, 14, 71888.

[289] D. A. Hines, E. R. Darzi, E. S. Hirst, R. Jasti, P. V. Kamat, The Journal of Physical Chemistry A 2015, 119, 298083.

[290] E. R. Darzi, E. S. Hirst, C. D. Weber, L. N. Zakharov, M. C. Lonergan, R. Jasti, ACS Central Science 2015, 1, 6335 .

[291] J. Wu, Y. Kan, Z. Xue, J. Huang, P. Chen, X. Yu, Z. Guo, Z. Su, Journal of Materials Chemistry C 2017, 5, 359088.

[292] Y. Olivier, J.-C. Sancho-García, L. Muccioli, G. DAvino, D. Beljonne, The Journal of Physical Chemistry Letters 2018, 9, 206149. 
[293] X.-K. Chen, D. Kim, J.-L. Brédas, Accounts of Chemical Research 2018, 51, 92215.

[294] A. Endo, K. Sato, K. Yoshimura, T. Kai, A. Kawada, H. Miyazaki, C. Adachi, Applied Physics Letters 2011, 98, 842.

[295] H. Uoyama, K. Goushi, K. Shizu, H. Nomura, C. Adachi, Nature 2012, 492, 7428234.

[296] M. Y. Wong, E. Zysman-Colman, Advanced Materials 2017, 29, 221605444.

[297] Y. Liu, C. Li, Z. Ren, S. Yan, M. R. Bryce, Nature Reviews Materials 2018, 3, 418020.

[298] J. Eng, B. A. Laidlaw, T. J. Penfold, Journal of Computational Chemistry 2019, 40, 252191.

[299] S. Hirata, M. Head-Gordon, Chemical Physics Letters 1999, 314, 3-4 291.

[300] A. Chantzis, A. D. Laurent, C. Adamo, D. Jacquemin, Journal of Chemical Theory and Computation 2013, 9, 104517.

[301] M. Moral, L. Muccioli, W.-J. Son, Y. Olivier, J.-C. Sancho-García, Journal of Chemical Theory and Computation 2015, 11, 1168.

[302] S. Grimme, F. Neese, The Journal of Chemical Physics 2007, $127,15154116$.

[303] A. Ottochian, C. Morgillo, I. Ciofini, M. J. Frisch, G. Scalmani, C. Adamo, Journal of Computational Chemistry 2020, 41, 131242.

[304] M. Head-Gordon, R. J. Rico, M. Oumi, T. J. Lee, Chemical Physics Letters 1994, 219, 1-2 21.

[305] O. Christiansen, H. Koch, P. Jørgensen, Chemical Physics Letters 1995, 243, 5-6 409.

[306] A. Hellweg, S. A. Grün, C. Hättig, Physical Chemistry Chemical Physics 2008, 10, 284119.

[307] M. Wormit, D. R. Rehn, P. H. Harbach, J. Wenzel, C. M. Krauter, E. Epifanovsky, A. Dreuw, Molecular Physics 2014, 112, 5-6 774.

[308] R. F. Fink, J. Seibt, V. Engel, M. Renz, M. Kaupp, S. Lochbrunner, H.-M. Zhao, J. Pfister, F. Würthner, B. Engels, Journal of the American Chemical Society 2008, 130, 3912858.

[309] A. Schubert, V. Settels, W. Liu, F. Würthner, C. Meier, R. F. Fink, S. Schindlbeck, S. Lochbrunner, B. Engels, V. Engel, The Journal of Physical Chemistry Letters 2013, 4, 5792.

[310] F. Plasser, B. Thomitzni, S. A. Bäppler, J. Wenzel, D. R. Rehn, M. Wormit, A. Dreuw, Journal of Computational Chemistry 2015, 36, 211609.

[311] Y. Olivier, M. Moral, L. Muccioli, J.-C. Sancho-García, Journal of Materials Chemistry C 2017, 5,235718 .

[312] C. A. Guido, P. Cortona, B. Mennucci, C. Adamo, Journal of Chemical Theory and Computation 2013, 9, 73118.

[313] C. A. Guido, P. Cortona, C. Adamo, The Journal of Chemical Physics 2014, 140, 10104101.

[314] C. Adamo, T. Le Bahers, M. Savarese, L. Wilbraham, G. García, R. Fukuda, M. Ehara, N. Rega, I. Ciofini, Coordination Chemistry Reviews 2015, 304166.

[315] R. L. Martin, The Journal of Chemical Physics 2003, 118, 114775.

[316] A.-R. Allouche, Journal of Computational Chemistry 2011, 32, 1174.

[317] T. Lu, F. Chen, Journal of Computational Chemistry 2012, 33, 5580.

[318] T. Etienne, X. Assfeld, A. Monari, Journal of Chemical Theory and Computation 2014, 10, 9 3896.

[319] T. Etienne, X. Assfeld, A. Monari, Journal of Chemical Theory and Computation 2014, 10, 9 3906. 


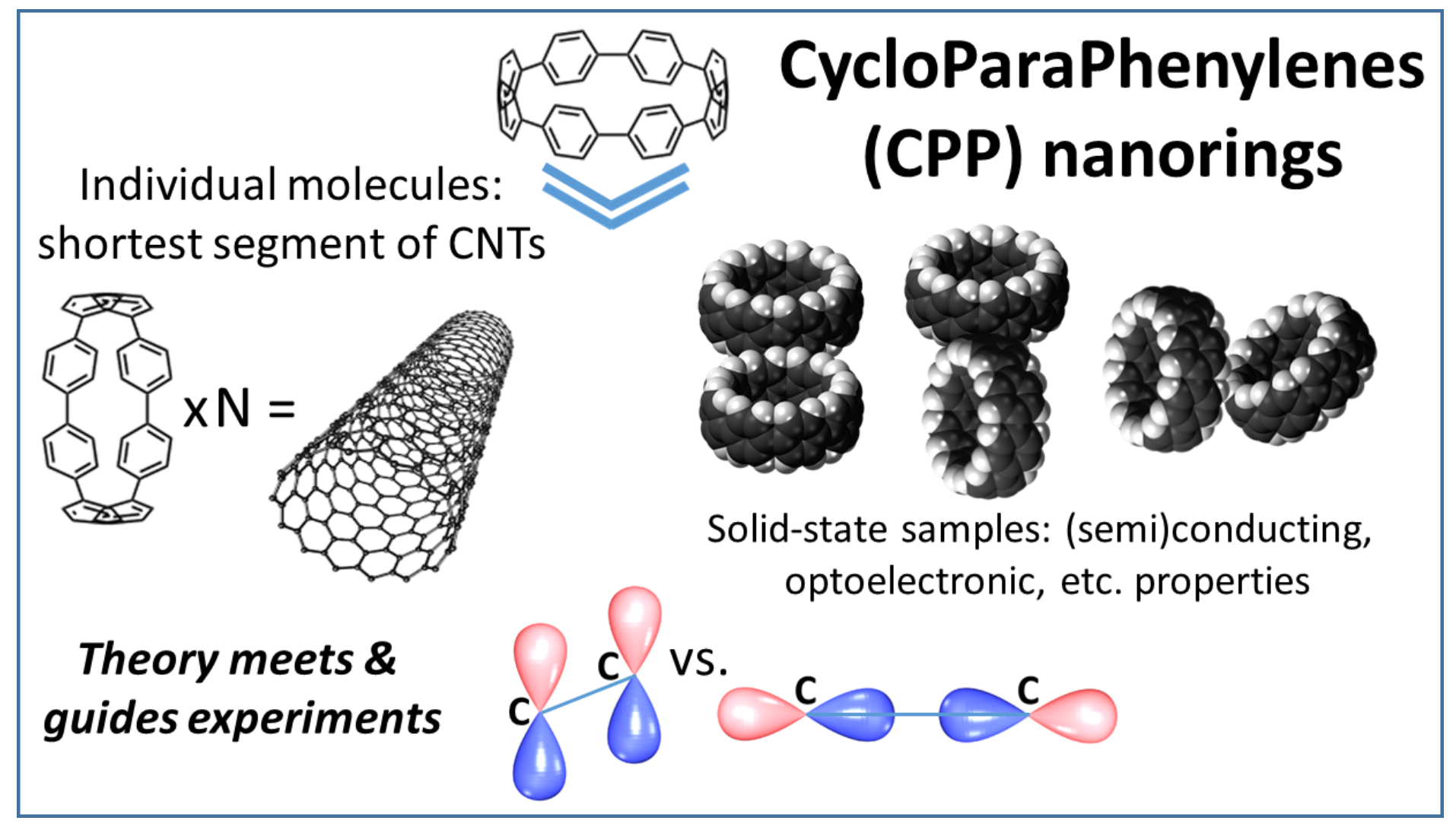

Figure 1: Summary of the content, emphasizing the role of theoretical studies for the deep understanding of the interplay between single-molecule and supramolecular properties of cyclic organic nanorings (CPPs). 


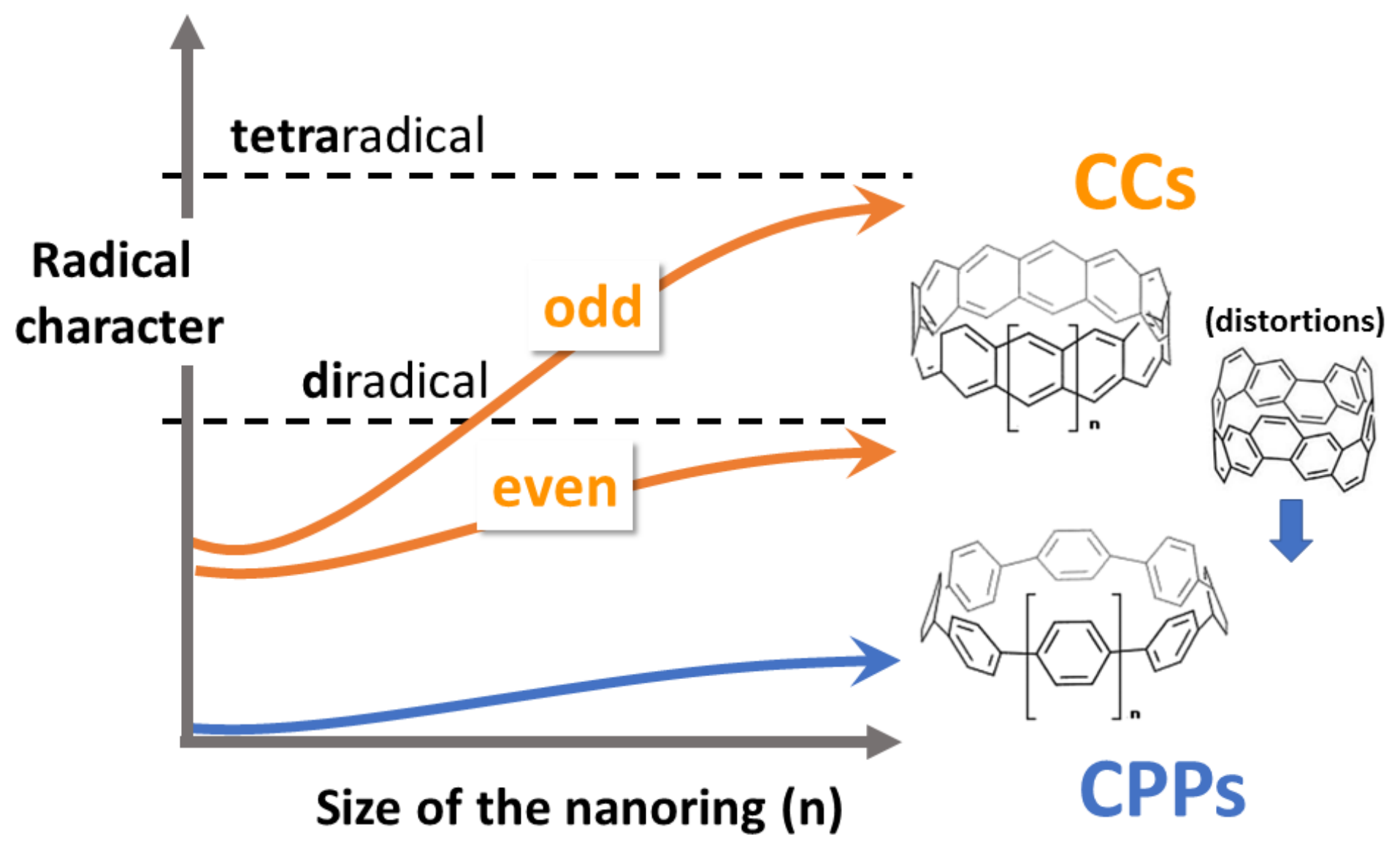

Figure 2: Sketch of the differences in the radical-like character of cyclic compounds, with CPPs (CCs) exhibiting low (moderate to high) character. Topological defects help to decrease the radicaloid nature of CCs affording thus their synthesis. Adapted from [Ref. [104]] with permission from the PCCP owner societies. 


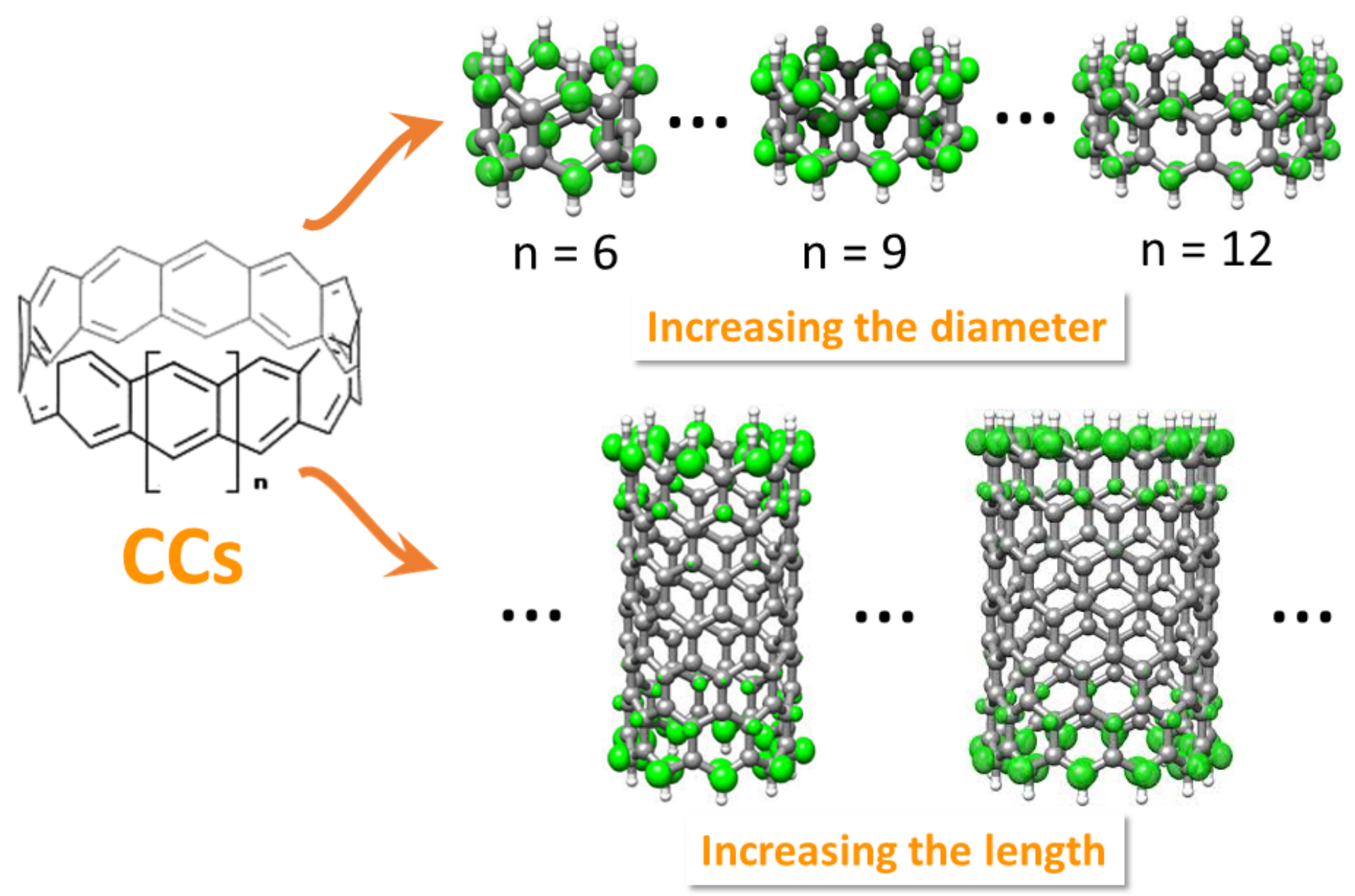

Figure 3: Isocontour plots $\left(\sigma=0.005 \mathrm{e} \cdot \mathrm{bohr}^{-3}\right)$ of the real-space distribution of strongly correlated electrons for CCs of increasing diameter and length (i.e., short zigzag CNTs). Adapted from ${ }^{[\text {Ref. }}{ }^{[106]]}$ with permission from the PCCP owner societies. 


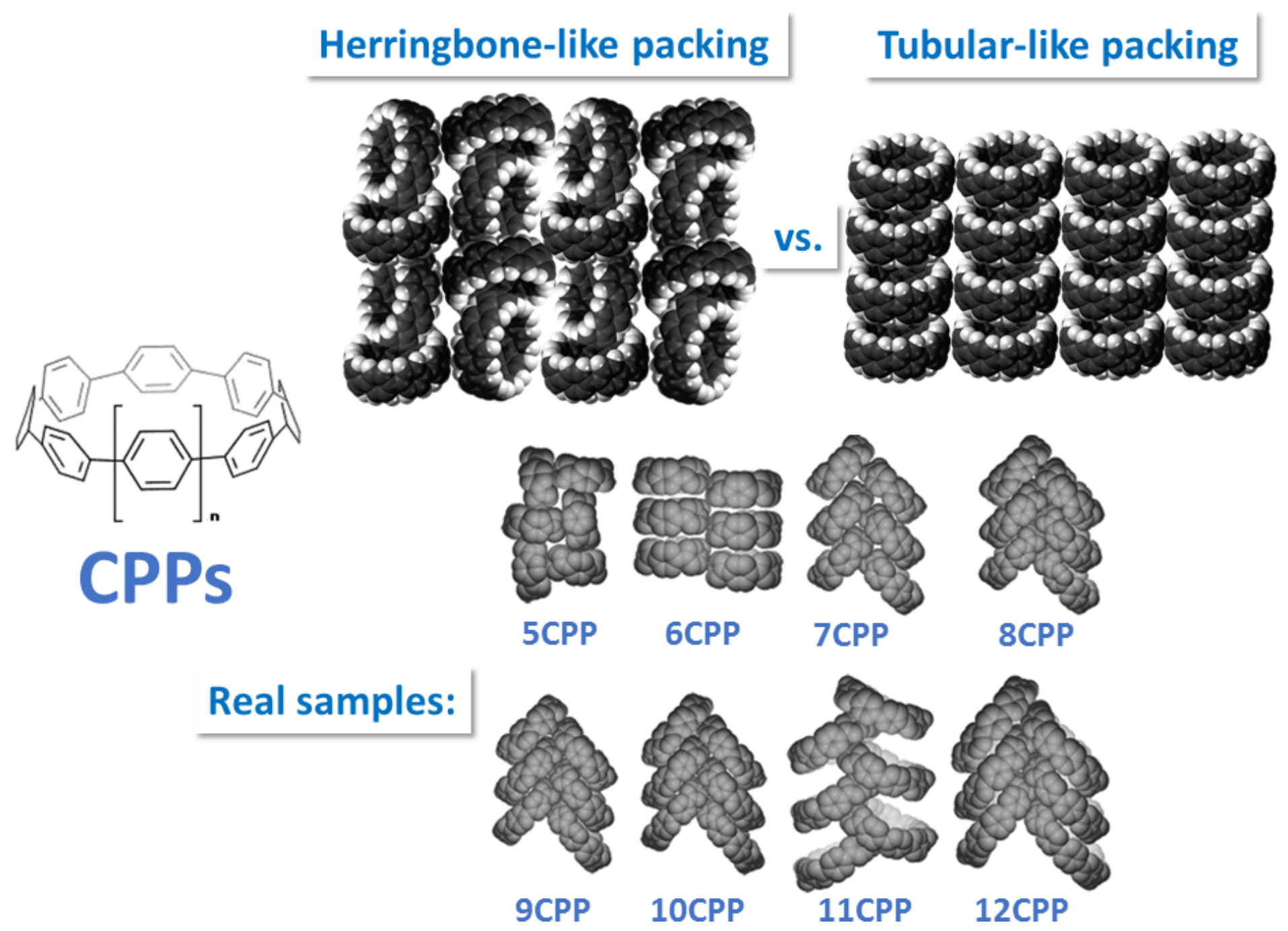

Figure 4: Supramolecular microstructures found in CPPs solid-state (experimental) samples, as a function of the nanoring size. 


\section{Molecule-surface interactions}
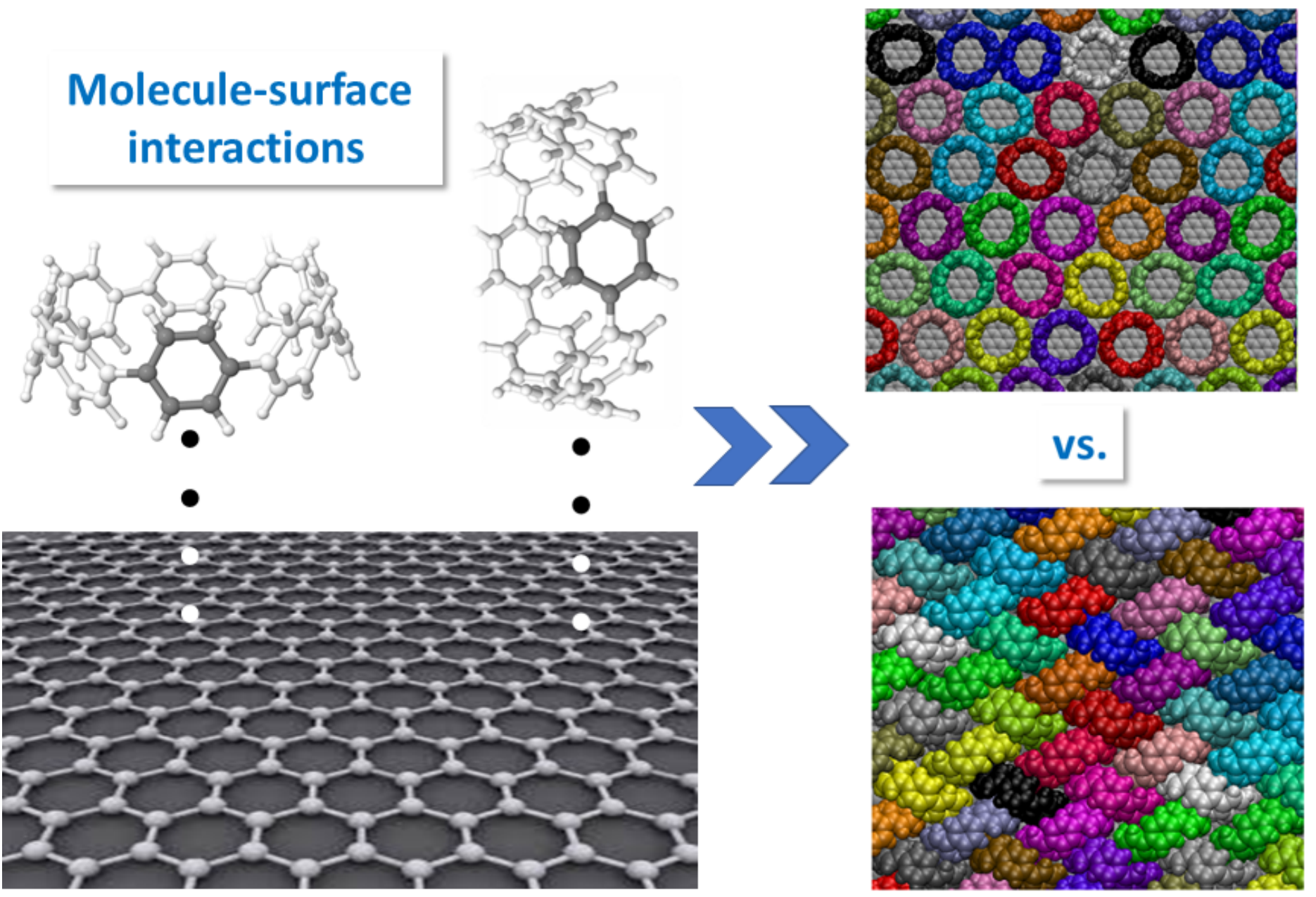

\section{Monolayer formation}

Figure 5: Different molecule-substrate orientations, emphasizing the dominant $\mathrm{CH} \cdots \pi$ and $\pi \cdots \pi$ interactions, and super-

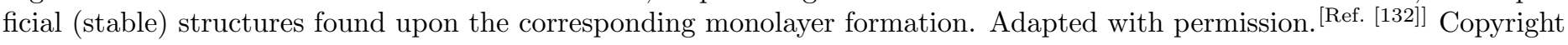
2019, Wiley-VCH. 
(a)

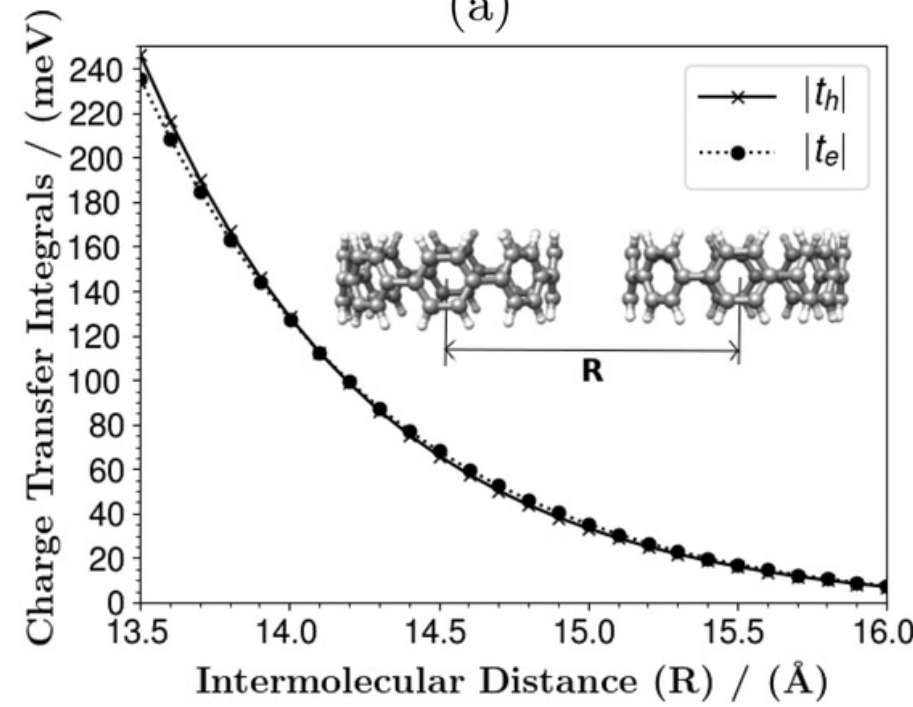

(c)

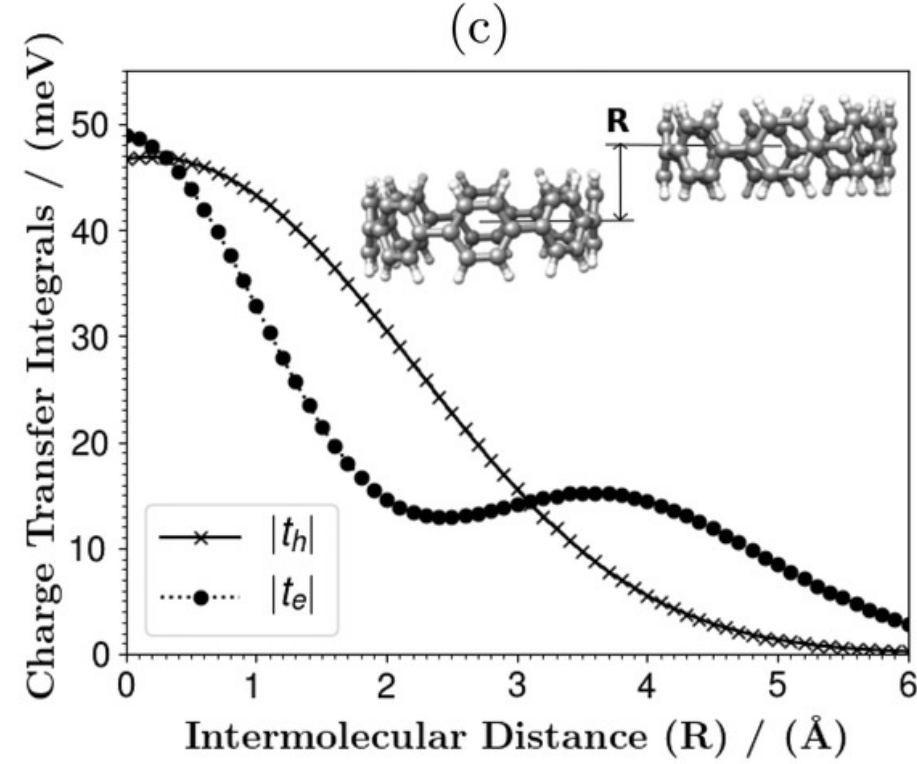

(e)

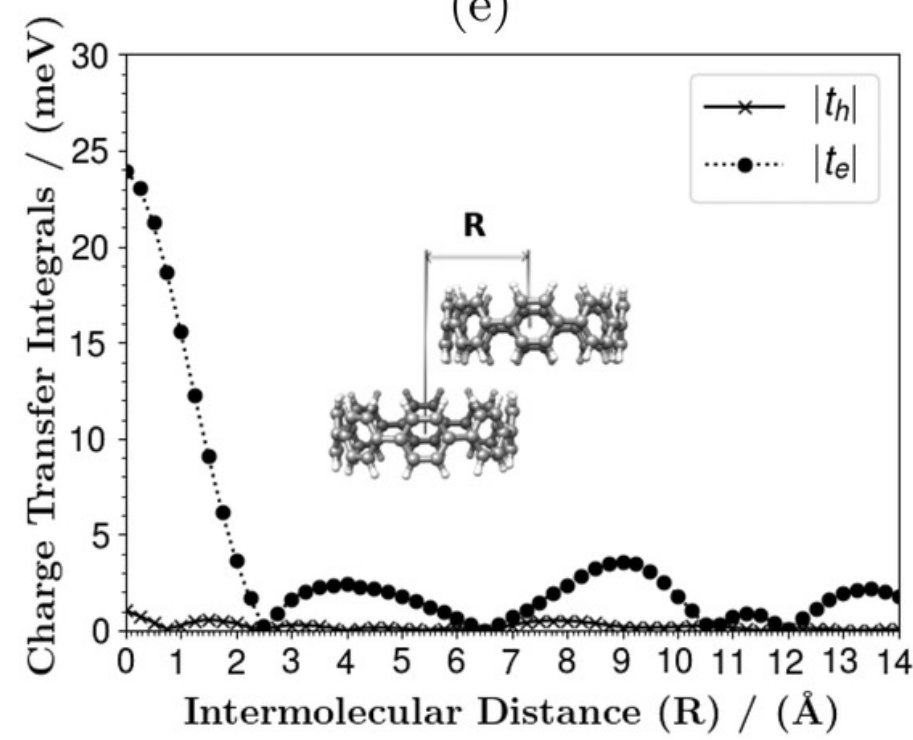

(b)

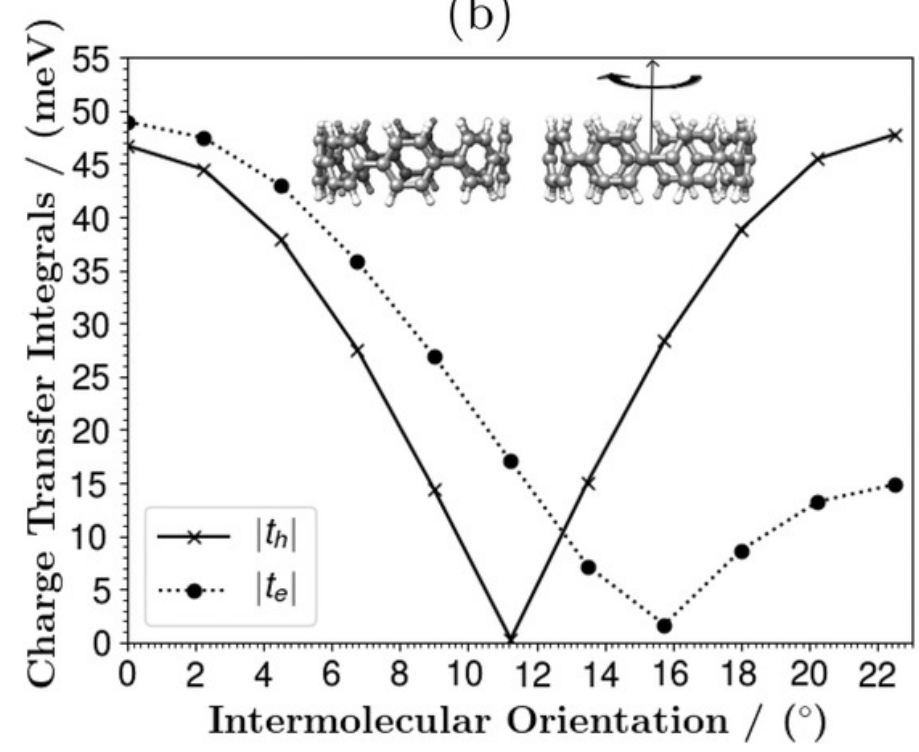

(d)

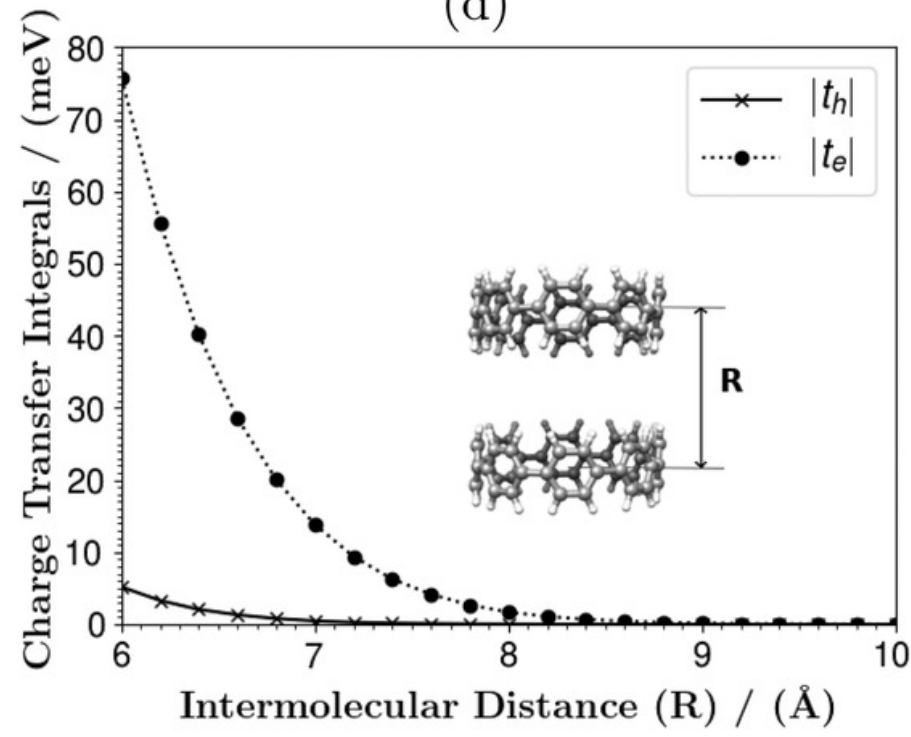

(f)

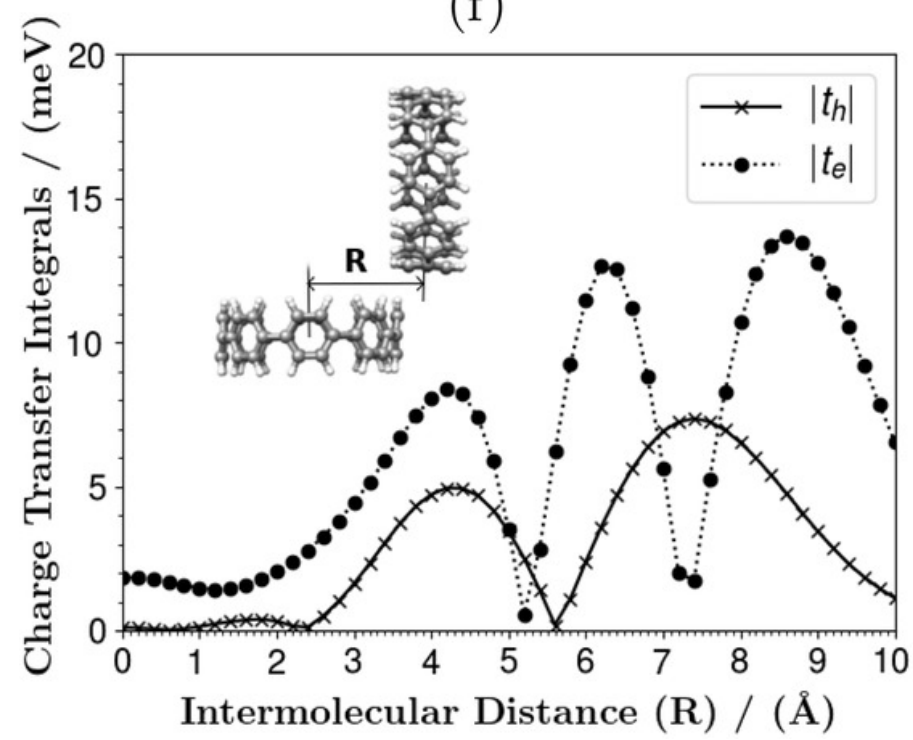

Figure 6: Dependence of electronic coupling values between neighbouring 8CPP molecules oriented as: (a) facetoface (or cofacial) configuration; (b) rotated cofacial configuration; (c) slipped cofacial configuration; (d) tubular-like configuration; (e) displaced tubular-like configuration; (f) herringbone-like configuration. Reproduced with permission. ${ }^{[R e f . ~[132]]}$ Copyright 2019, Wiley-VCH. 


\section{D-A design strategy: altering CPP properties}
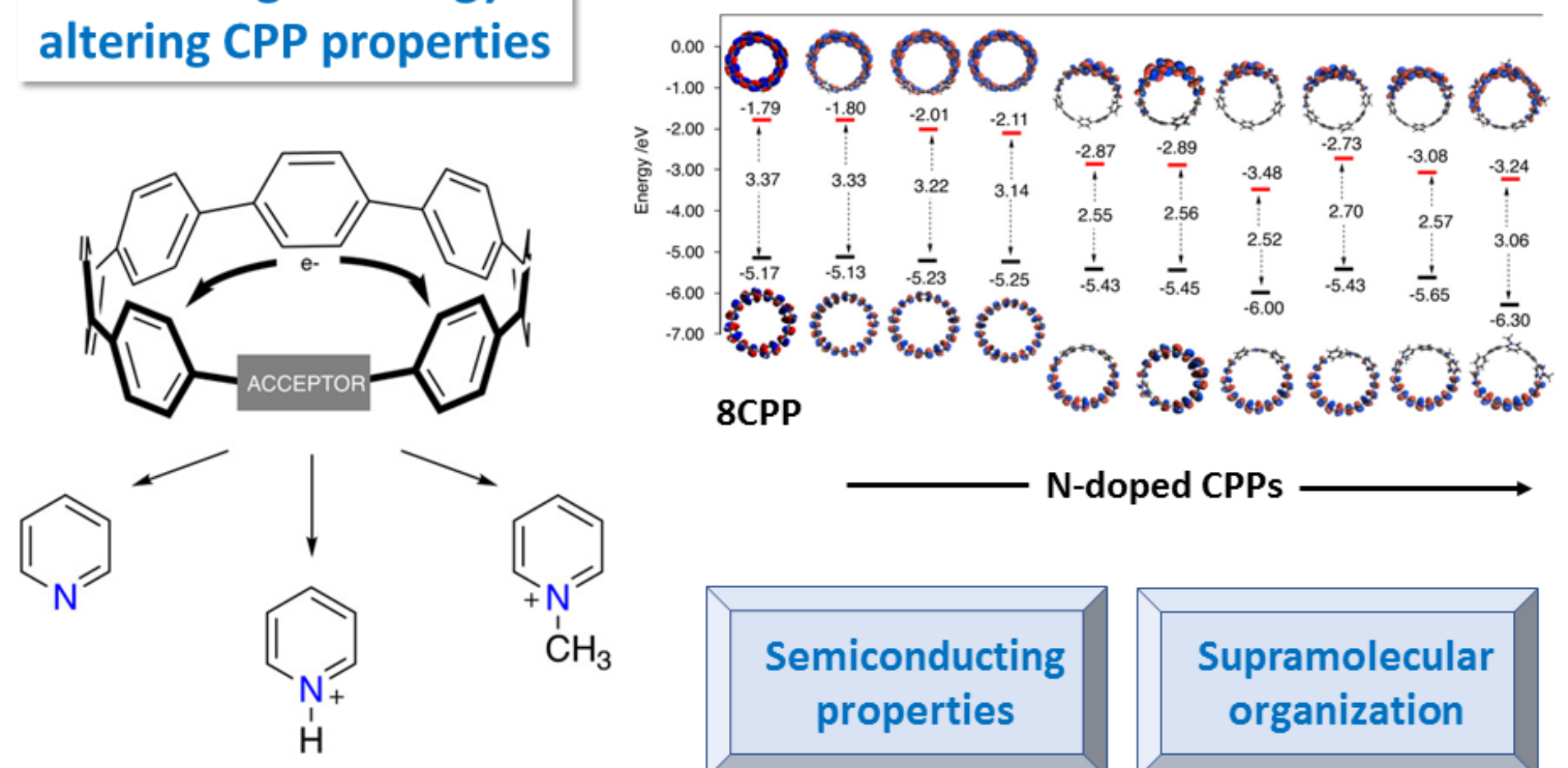

$\mathrm{N}$-doped CPPs
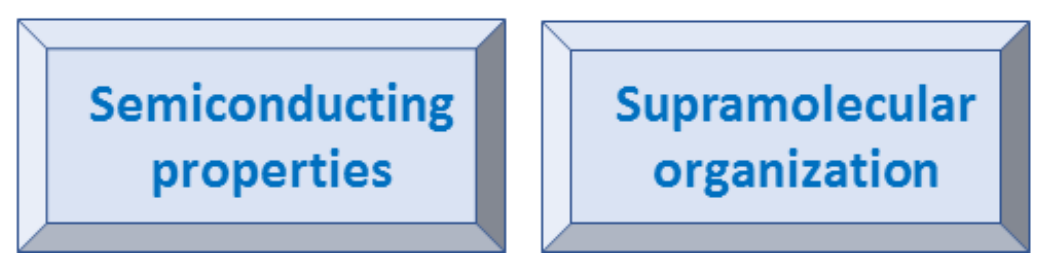

Figure 7: Functionalization of CPPs to obtain N-doped derivatives, altering single-molecule and supramolecular properties. Adapted from [Ref. [125]] Copyright 2018, Wiley-VCH. 


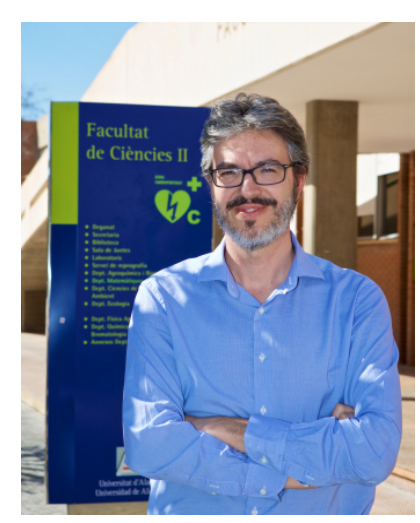

Juan-Carlos Sancho-García completed a Ph.D. in Quantum Chemistry (2001) at the University of Alicante (Spain). After stays in Prague (Czech Republic) and Mons (Belgium) he obtained a tenure-track "Ramó n y Cajal" research position (2005) at the University of Alicante and holds a permanent Professorship (2010) in Physical Chemistry. He has been named Visiting Professor of Universities of Limoges (France), Mons (Belgium), and Paris (France). His main research interests concern developments and applications of DFT, with focus on complex materials and nanoscale properties.

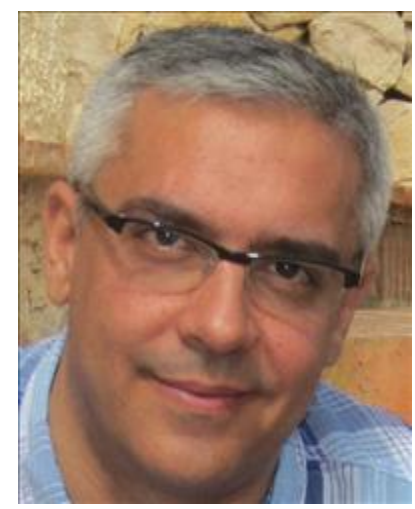

Ángel José Pérez-Jiménez obtained his Ph.D. degree in Quantum Chemistry in 1998 at the University of Alicante (Spain). After stays in Clausthal-Zellerfeld (Germany) and Bologna (Italy) he obtained in 2003 a "Ramón y Cajal" senior research position at the University of Alicante (Spain), where he holds a permanent Professorship in Physical Chemistry since 2009. His research has mainly focused on the development and application of computational chemistry and physics to study molecules, materials, and nanodevices. 


\section{Table of Contents

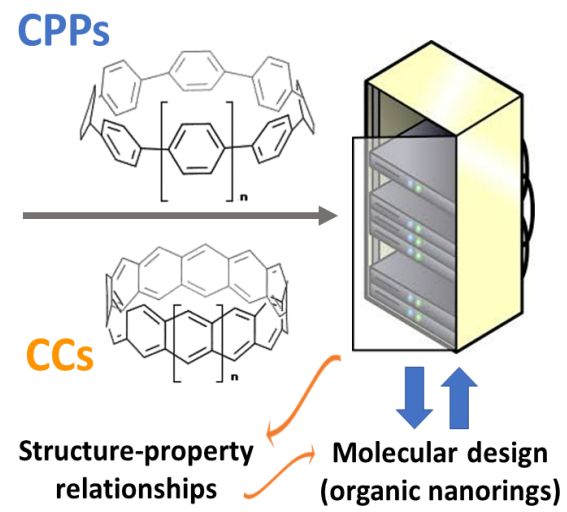

Cyclic organic nanorings are promising materials with envisioned outstanding nanotechnological applications. We summarize here how modern theoretical methods can provide insights for materials design, as well as for the understanding of the underlying structure-property relationships. 